\title{
PROGRAMMING A RANDOMIZED DEPENDENT GROUP CONTINGENCY AND COMMON STIMULI TO PROMOTE DURABLE BEHAVIOR CHANGE
}

by

THOMAS A. CARIVEAU

\section{A DISSERTATION}

Presented to the Department of Special Education and Clinical Sciences and the Graduate School of the University of Oregon

in partial fulfillment of the requirements

for the degree of

Doctor of Philosophy

June 2016 


\section{DISSERTATION APPROVAL PAGE}

Student: Thomas A. Cariveau

Title: Programming a Randomized Dependent Group Contingency and Common Stimuli to Promote Durable Behavior Change

This dissertation has been accepted and approved in partial fulfillment of the requirements for the Doctor of Philosophy degree in the Department of Special Education and Clinical Sciences by:

Dr. Tiffany Kodak

Dr. Laura Lee McIntyre

Dr. Roland H. Good III

Dr. Atika Khurana

and

Scott L. Pratt

Dean of the Graduate School

Original approval signatures are on file with the University of Oregon Graduate School. Degree awarded June 2016. 
(C) 2015 Thomas A. Cariveau

This work is licensed under a Creative Commons

\section{Attribution-NonCommercial-NoDerivs (United States) License}




\section{DISSERTATION ABSTRACT}

Thomas A. Cariveau

Doctor of Philosophy

Department of Special Education and Clinical Sciences

June 2016

Title: Programming a Randomized Dependent Group Contingency and Common Stimuli to Promote Durable Behavior Change

Students may engage in behavior during instruction that impacts the acquisition of skills. Intervening on student behavior using group contingencies may be more efficacious than other intervention methods. Directly programming for generalization of treatment effects may increase the durability of behavior change and further increase the efficacy of group contingencies. The current study examined the effect of a randomized dependent group contingency and programming common stimuli on levels of academic engagement and problem behavior for second-grade participants receiving small-group reading and writing instruction. The results showed that a randomized dependent group contingency increased the academic engagement of primary participants and several of the other participants during small-group instruction. The findings also showed that high levels of academic engagement were maintained when common stimuli were present and the dependent group contingency was withdrawn. 


\section{CURRICULUM VITAE}

NAME OF AUTHOR: Thomas A. Cariveau

GRADUATE AND UNDERGRADUATE SCHOOLS ATTENDED:

University of Oregon, Eugene

University of Minnesota, Duluth

DEGREES AWARDED:

Doctor of Philosophy, School Psychology, 2016, University of Oregon

Master of Science, Special Education, 2014, University of Oregon

Bachelor of Science, Psychology, 2011, University of Minnesota Duluth

\section{AREAS OF SPECIAL INTEREST:}

Early intervention with individuals with developmental disabilities

Language interventions for individuals with developmental disabilities

Durability of behavior change in extinction

Treatment of problem behavior for individuals with developmental disabilities

\section{PROFESSIONAL EXPERIENCE}

Pre-Doctoral Intern, Marcus Autism Center, Atlanta, Georgia, July 2015- Current

Guest Reviewer, Journal of Applied Behavior Analysis, August 2014 - Current

Supervised College Teacher, SPSY 661: Principles and Practices of School

Psychology, University of Oregon, Eugene, September 2014 - December 2014

Supervised College Teacher, SPSY 609: Academic and Behavioral Interventions Practicum, University of Oregon, Eugene, January 2014 - June 2014

Direct Interventionist, Academic and Behavioral Interventions Practicum, University of Oregon, Eugene, May 2012 - June 2014

Youth Support Specialist, Project SWIFT, Oregon Social Learning Center, Eugene, August 2012 - June 2015

\section{GRANTS, AWARDS, HONORS:}

Graduate Teaching Fellow, School Psychology Assessment Sequence, University of Oregon, Eugene, September 2014- June 2015 
Graduate Teaching Fellow, School Psychology Assessment Sequence, University of Oregon, Eugene, September 2013 - June 2014

Student Presenter Grant, Society for the Advanced of Behavior Analysis, February 2013

Graduate Research Fellow, Educational and Community Supports, University of Oregon, Eugene, September 2011 - December 2011

Departmental Honors, University of Minnesota Duluth, 2011

\section{PUBLICATIONS}

LeBlanc, B., Kodak, T., Cariveau, T., \& Campbell, V. (under review). A Comparison of Computer-Assisted and Person-Based Tact Training for Children with Autism Spectrum Disorders.

Buchanan, R., Ruppert, T., \& Cariveau, T. (under review). Transition Supports for AtRisk Students: A Case Example.

Garbacz, S. A., Cariveau, T., \& Barrett, E. (under review) Examining the Treatment Validation Consultation Model with Two Case Studies.

Cariveau, T., Kodak, T., \& Campbell, V. (accepted for publication). The Effects of Intertrial Interval and Instructional Format on Skill Acquisition and Maintenance for Children with Autism. Journal of Applied Behavior Analysis.

Haq, S. S., Kodak, T., Kurtz-Nelson, E., Porritt, M., Rush, K., \& Cariveau, T. (2015). Comparing the effects of massed and distributed practice on skill acquisition for children with autism. Journal of Applied Behavior Analysis. 


\section{ACKNOWLEDGMENTS}

First, I wish to express my gratitude to Dr. Tiffany Kodak for her mentoring and unwavering guidance throughout this project and my graduate training. I chose to pursue my doctorate in school psychology largely as a result of the opportunities and encouragement that Dr. Kodak provided. I am incredibly grateful for the countless hours that she has spent supporting me throughout my graduate career and I look forward to any and all opportunities to work with her in the future.

I am also grateful for my dissertation committee members, Dr. Laura Lee McIntyre, Dr. Tiffany Kodak, Dr. Roland Good III, and Dr. Atika Khurana and their support throughout this process. I am indebted to each of you for the guidance that you have provided me in my graduate training and this project.

I would like to acknowledge the Center on Teaching and Learning and the reading clinic staff. Thank you for your willingness to welcome this project into your program and the opportunities that you provide to students in our program.

Finally, to all of my colleagues within the school psychology and special education programs that assisted with various aspects of the current study, I am thankful for your continued support with this project and many others. I would like to specifically acknowledge Rachel Border, Jacqueline Kammer, Eva Kurtz-Nelson, Jake Mahon, Samantha Moberg, Manuel Monzalve, Marilynn Porritt, Margaret Rosencrans, Traci

Ruppert, Kristin Rush, Michael Schwartz, Claudia Sariah Suarez Pedraza, and Patricia Zemantic. I look forward to the opportunity to work with each of you in your bright futures. 
Dedicated to my family and many mentors.

viii 


\section{TABLE OF CONTENTS}

Chapter

Page

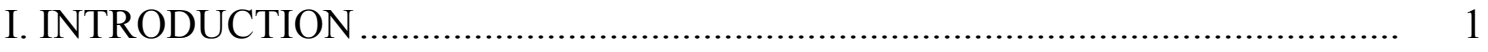

Academic Engagement ...................................................................... 1

Group Contingency ............................................................................. 3

Generalization and Response Maintenance ................................................. 8

Research Questions .............................................................................. 12

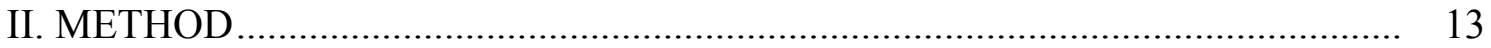

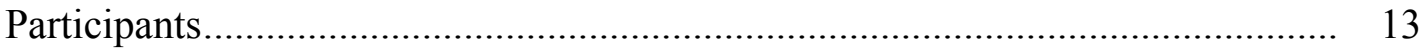

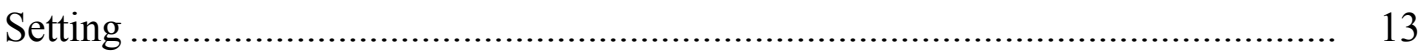

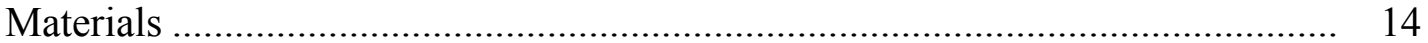

Experimental Design..................................................................... 14

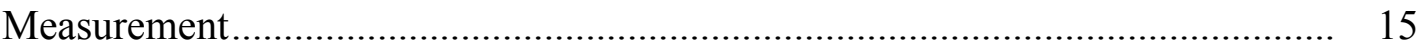

Dependent Variables ....................................................................... 15

Independent Variables .................................................................... 17

Interobserver Agreement and Fidelity of Implementation........................... 18

Preference Assessment........................................................................... 21

Contingency Space Analysis...................................................................... 22

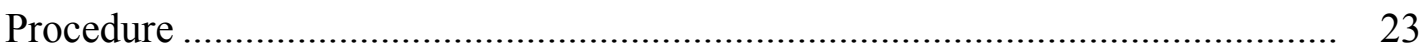

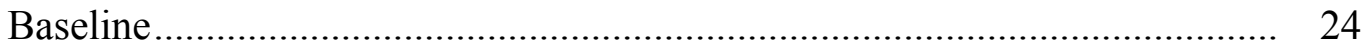

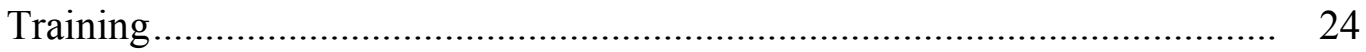

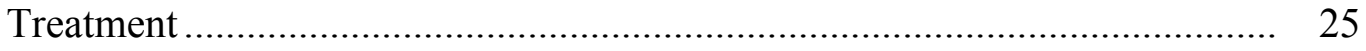

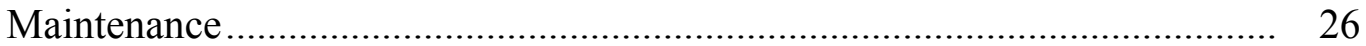




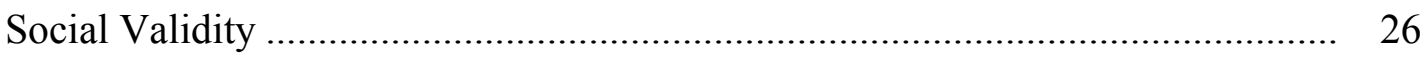

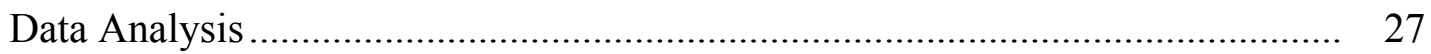

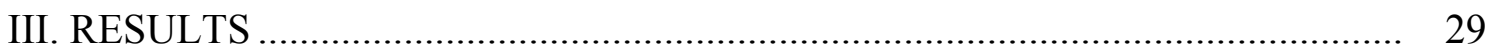

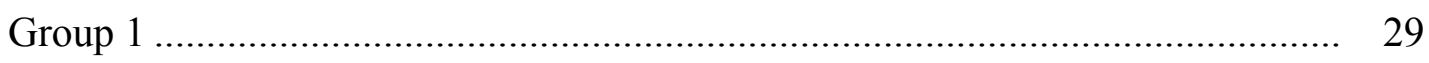

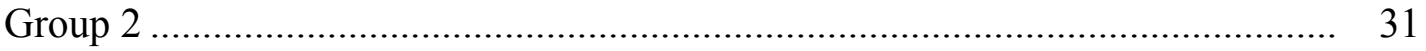

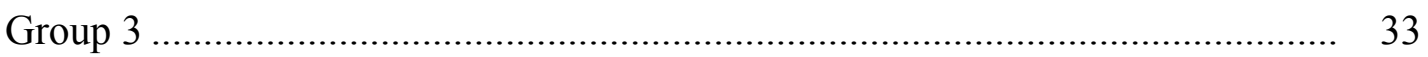

Contingency Space Analysis.......................................................................... 35

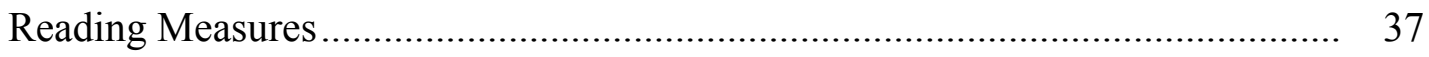

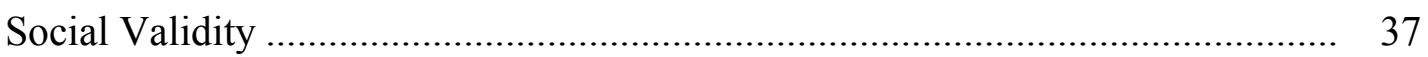

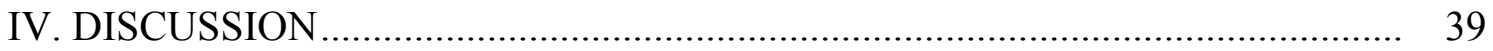

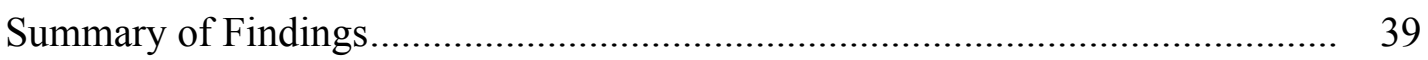

Dependent Group Contingencies ............................................................... 40

Programming Common Stimuli and Maintenance ………….......................... 42

Problem Behavior ………………………………………..................... 47

Academic Engagement ……………....................................................... 49

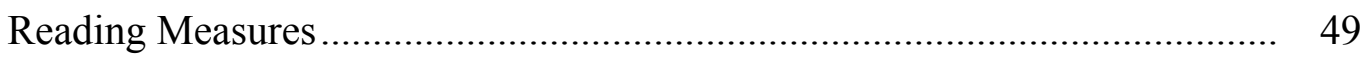

Social Validity ................................................................................. 51

Behavioral Mechanisms........................................................................... 52

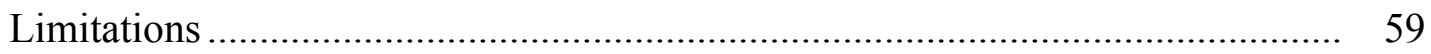

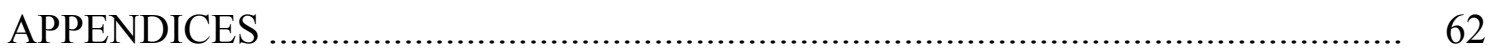

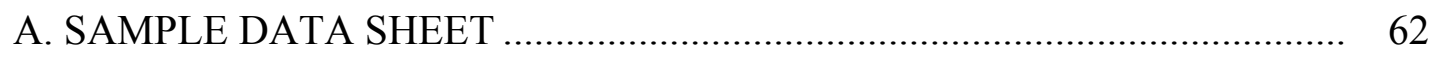

B. FIDELITY OF IMPLEMENTATION CHECKLIST ……............................... 63 
C. MSWO PREFERENCE ASSESSMENT DATA SHEET …………................. 63

D. CALCULATING CONDITIONAL PROBABILITIES ................................... 65

E. TREATMENT EVALUATION INVENTORY SHORT-FORM..................... 66

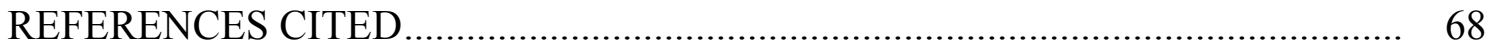




\section{LIST OF FIGURES}

Figure

Page

1. Percentage of session with academic engagement and problem behavior

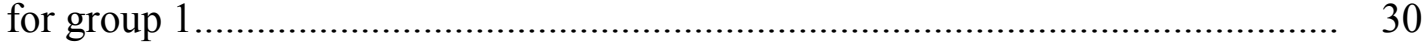

2. Percentage of session with academic engagement and problem behavior

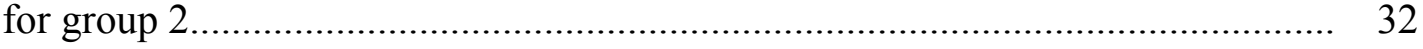

3. Percentage of session with academic engagement and problem behavior

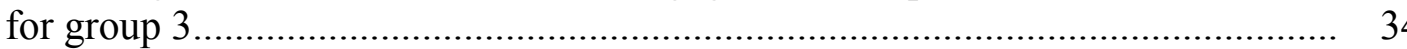




\section{LIST OF TABLES}

Table

Page

1. Mean and range of instructor ratings on the Treatment Evaluation

Inventory- Short Form 38 


\section{CHAPTER I}

\section{INTRODUCTION}

The field of education is charged with teaching all students to read, with particular importance being placed on reading before third-grade (Coyne, Kame'enui, \& Simmons, 2004; Good, Kaminski, Simmons, \& Kame’enui, 2001). Nevertheless, the National Reading Panel (2000) reported that more than $17.5 \%$ of students experience reading difficulties before third-grade. Children who display low levels of attention have a higher risk for reading difficulties (Stephenson, Parrila, Georgiou, \& Kirby, 2008; Sims \& Lonigan, 2013). Thus, identifying interventions that increase attending during reading instruction may lead to improved reading outcomes.

\section{Academic Engagement}

Academic engagement has been defined as alterable behavior that contributes to academic achievement or, more simply, what a student does while being taught (Greenwood, Horton, \& Utley, 2002). Prior research has used the term academic engagement to refer to a number of discrete behaviors such as being on-task (e.g., Carnine, 1976; Hallahan, Lloyd, Kosiewicz, Kauffman, \& Graves, 1979), talking to a teacher about academic materials (e.g., Cobb, 1972), attending to materials (e.g., Cobb, 1972) and compliance (e.g., Cobb, 1972; Athens, Vollmer, \& St. Peter Pipkin, 2007). These task-related behaviors contribute to greater academic outcomes (Carnine, 1976; Greenwood et al., 2002; Hallahan et al., 1979). For example, Carnine found a positive relationship between correct responding and participation in the task. Similarly, Hallahan et al. (1979) found that self-monitoring of attending to a task led to higher levels of ontask behavior and correct responses per minute on handwriting and math tasks for a 
student with a learning disability. Thus, increasing academic engagement is an important goal during instruction.

One way to increase academic engagement is to reinforce this behavior and remove or reduce reinforcement for some competing behavior. Lane, Smither, Huseman, Guffey, and Fox (2007) showed that an intervention that included self-monitoring and attention for academic engagement increased rates of academic engagement and decreased rates of disruptive behavior for a kindergarten student with attentionmaintained problem behavior. This finding is consistent with the extant literature on differential reinforcement procedures. For example, Kodak, Miltenberger, and Romaniuk (2003) evaluated the effects of differential reinforcement of other behavior (DRO) on levels of problem behavior and compliance. The authors provided a break from demands contingent on the absence of problem behavior. This intervention led to increased levels of compliance to instructor demands and reductions in the rate of problem behavior for two students with autism.

Although many prior studies on differential reinforcement implemented functionbased treatment to reduce problem behavior and increase compliance (e.g., Call, Pabico, Findley, \& Valentino, 2011; Iwata, Pace, Edwards, Cowdery, \& Miltenberger, 1994; Roane, Falcomata, \& Fisher, 2007; Romaniuk, Miltenberger, Conyers, Jenner, Jurgens, \& Ringenberg, 2002), some research shows that using tangibles or edibles as reinforcers also can lead to improved outcomes for children (e.g., Lalli et al., 1999; Lomas, Fisher, \& Kelley, 2010). For example, Lomas et al. found that praise and tangible items provided on a fixed-time schedule reduced problem behavior and increased compliance for children with escape-maintained problem behavior. Nevertheless, limitations of prior 
studies using differential reinforcement to reduce problem behavior are that intervention was rarely delivered in a classroom setting and the intervention was conducted in a oneon-one format. These limitations may affect the external validity of these findings to child behavior in groups and to individuals receiving intervention in classroom settings. Additional research evaluating the effects of tangibles and other arbitrary reinforcers on group behavior in classroom settings is warranted.

One intervention technique that is more frequently used with groups of students in classroom settings, and that directly reinforces higher levels of academic engagement, is group-oriented contingencies.

\section{Group Contingency}

As schools have experienced increases in accountability for student outcomes, efficacious means of promoting appropriate behavior and academic achievement for larger groups of students are necessary (Sadler \& Sugai, 2009). Group-oriented contingencies, referred to as "group contingencies" for the remainder of this paper, are behavior-management techniques that are applied to groups to alter individual or groupwide behavior (Litow \& Pumroy, 1975).

There are numerous benefits of using group contingencies (Gresham \& Gresham, 1982). For example, group contingencies allow one instructor to implement an intervention to groups of students. Within a 3-tiered framework at the classroom level, group contingencies would likely be considered a Tier I intervention, or universal support (Simonsen, Britton, \& Young, 2010). In support of this notion, Embry (2002) described group contingencies, specifically the Good Behavior Game, as a form of behavioral prevention. The author posits that this behavior management technique, applied to all 
students as a preventative measure, may reduce behavioral risk for later substance use, antisocial behavior, and other social consequences.

Group contingencies have been identified as a more efficient system of intervening, in comparison to individualized programs (Gresham \& Gresham, 1982; Herman \& Tramontana, 1971; Litow \& Pumroy, 1975; Tingstrom, Sterling-Turner, \& Wilczynski, 2006), and at least as effective as individualized interventions (Tingstrom et al., 2006). Herman and Tramontana (1971) compared the effectiveness of individual and group contingencies in a rural Head Start classroom. They observed similar decreases in inappropriate behavior in both the individual and group-contingency conditions. The authors stated that the dramatic changes in student behavior observed in both groups suggest that group contingencies are both efficacious and efficient.

Group contingencies also can be used to address multiple functions of behavior simultaneously. In a review of classroom-based group contingencies, Litow and Pumroy (1975) described the benefit of group contingencies on the social consequences that may be available for problem behavior in classrooms. For example, group contingencies may decrease levels of adult attention for problem behavior by having the teacher attend to appropriate behavior instead. Teachers using the Caught Being Good Game scanned the classroom on a specific time schedule and provided praise and points to students engaging in academic behavior. The points earned for appropriate behavior were exchanged for preferred classroom activities and opportunities to interact with peers (Wright \& McCurdy, 2011).

In the Good Behavior Game, which also involves implementing group contingencies in classroom settings, children earn breaks, tangibles, and receive adult 
attention for being on-task during instruction (Leflot, van Lier, Onghena, \& Hilde, 2013). Thus, multiple types of reinforcers are available to children who display appropriate behavior in classrooms using these examples of group contingencies.

Three specific types of group contingencies have been described in the literature (Gresham \& Gresham, 1982; Litow \& Pumroy, 1975). Independent group contingencies are based on an individual's behavior, and reinforcement is provided to the individuals who meet the criterion for reinforcement. For example, each student in the classroom who earns 5 points in a specified time period receives reinforcement. Interdependent group contingencies are based on the level of a group's performance, and all students receive reinforcement if some proportion of the group meets a predetermined criterion. Thus, all children in the class receive a free-play period if $90 \%$ of the children return their signed parent conference forms by Friday. Finally, in dependent group contingencies, all or none of the students receive a consequence based on one student's or a small-group's performance of some behavior. For example, if Arjun earns 10 points during reading, the whole class receives an extra 5 min of recess.

Although there is considerably less research conducted on dependent group contingencies than independent or interdependent group contingencies, previous research suggests that this type of contingency is effective in increasing positive student behavior (e.g., Williamson, Campbell-Whatley, \& Lo, 2009). Gresham and Gresham (1982) compared dependent, interdependent, and independent group contingencies using a reversal design. During the dependent group contingency, the authors made access to reinforcement for two teams of students contingent on the behavior of two student captains who had the highest frequency of disruptive behavior. The frequency of class- 
wide disruptive behavior during the dependent group contingency was significantly lower than baseline levels. Similarly, Williamson et al. found that on-task behavior increased with the introduction of a dependent group contingency during individual seatwork for six $10^{\text {th }}$-grade African-American students receiving special education services.

In a study evaluating a variation of a dependent group contingency, Heering and Wilder (2006) showed increased levels and maintenance of on-task behavior that was nearly double the observed level of behavior in baseline for third- and fourth-grade classrooms when the group contingency was implemented. The authors' procedures differed from previous research on dependent group contingencies because reinforcement was based on the behavior of students in rows of desks instead of based on a single student's behavior.

Prior research has demonstrated that dependent group contingencies are effective in increasing the positive behavior of all students in the classroom, as well as a particular student who is of primary concern within the classroom (Williamson, Campbell-Whatley, $\&$ Lo, 2009). For example, some studies have reported that the student may receive peer support so that the entire class will earn the reinforcer (e.g., Williamson, CampbellWhatley, \& Lo, 2009). Patterson (1965) anecdotally reported that the student's classmates applauded for the student when the goal was reached.

When designing dependent group contingencies, it may be beneficial to randomize certain aspects of the intervention (Hawkins, Musti-Rao, Hughes, Berry, \& McGuire, 2009). Heering and Wilder (2006) used a number of randomized components of group contingencies. Specifically, the authors randomly selected the reinforcer and the students who were observed for the dependent group contingency. Gresham and Gresham 
(1982) referred to these randomized components of group contingencies as "unknown" because students were not told who was being observed or what had been chosen as the reinforcer.

Theodore, Bray, and Kehle (2004) compared dependent, independent, and interdependent group contingencies with five students identified as having a Serious Emotional Disturbance. The authors evaluated randomized components across all types of group contingencies including the selection of a random student to be observed (i.e., dependent group contingency) and a random reinforcer. Using an alternating treatments design, the authors found that all three types of group contingencies led to lower and similar reductions in disruptive behavior across participants.

There are several benefits of using randomized dependent group contingencies. First, the randomized and unknown selection of reinforcers has been identified as contributing to student's motivation (Theodore et al., 2004). That is, when students are not aware of the specific item that will be selected from a pool of reinforcers, they may be more likely to engage in the target behavior in order to obtain a chance to have their preferred item selected (Popkin \& Skinner, 2003). Second, random selection of a reinforcement criterion may motivate students to display high levels of the target behavior because the criterion for reinforcement is unknown (Hawkins et al., 2009). Finally, the random selection of a student to observe also has been identified as important in avoiding negative social consequences when a particular student does not meet the criterion for the group contingency (Gresham \& Gresham, 1982).

Although a small number of previous studies have evaluated randomized dependent group contingencies and shown improvements in target behavior (e.g., 
Theodore et al., 2004), none of these studies measured maintenance of intervention outcomes or evaluated ways to promote maintenance of behavior change following the completion of intervention. Thus, additional research is needed to identify effective strategies to promote the maintenance and generalization of outcomes of randomized group contingencies.

\section{Generalization and Response Maintenance}

The generalization of behavior change is a fundamental goal of intervention within the fields of behavior analysis and education (Freeland \& Noell, 2002; Stokes \& Baer, 1977). Generalization is said to occur when the relevant behavior is displayed under different conditions than the training environment (Stokes \& Baer, 1977). Of particular interest is the durability of behavior change over time, or response maintenance (Baer, Wolf, \& Risley, 1968). Freeland and Noell (2002) said, “...parents and schools are seeking to create beneficial and enduring changes in children's behavior" (p. 6). Thus, interventions should include strategies to promote generalization and maintenance of behavior change. Stokes and Baer (1977) described nine strategies to program for generalization: (a) train and hope, (b) sequential modification, (c) introduce to natural maintaining contingencies, (d) train sufficient exemplars, (e) train loosely, (f) use indiscriminable contingencies, (g) program common stimuli, (h) mediate generalization, and (i) train to generalize.

Since the publication of the seminal article by Stokes and Baer (1977), researchers have examined the effectiveness and efficiency of most of these generalization strategies. One strategy for examining generalization described by Stokes and Baer (1977) was the "train and hope" method. This strategy is used when no direct 
programming for generalization occurs, but generalization is measured. Stokes and Baer (1977) identify that this is the most common generalization strategy evaluated in the literature, and this method was used in nearly half of the studies included in their review. In a more recent review of generalization strategies for social-skills interventions conducted with preschool children, Chandler, Lubeck, and Fowler (1992) found that 27\% of studies employed a "train and hope" strategy for promoting generalization. Limitations of this strategy include the reduced likelihood of generalization without direct programming and the lack of emphasis on the importance of directly training for generalization in these studies (Stokes \& Baer, 1977). Furthermore, authors may not report assessments of generalization if it doesn't occur because they did not directly program for generalization. Stokes and Baer (1977) emphasize the importance of reporting generalization outcomes, even if they're not observed and programming for generalization is not part of the study, as this practice may promote a better understanding of variables that impact the generalization of behavior.

Other strategies described by Stokes and Baer (1977) include direct training for generalization. Programming indiscriminable contingencies is one example of a strategy used to directly train for generalization of responding (Stokes \& Baer, 1977). There are several ways to program indiscriminable contingencies, one of which is programming delayed reinforcement. Delayed reinforcement involves increasing the duration of time between the target behavior and access to the reinforcer. Schwarz and Hawkins (1970) altered the posture, volume of speech, and rate of face-touching in a 12-year-old typically developing girl using video feedback and delayed reinforcement. Observations were conducted during math instruction at the beginning of the school day, and reinforcement 
was provided at the end of the day if her responding met the reinforcement criterion. The results showed improvements in target behavior during math instruction and generalization across class periods and at a one-month follow-up assessment.

The use of intermittent reinforcement is another way to program indiscriminable contingencies. Intermittent reinforcement has been shown to produce response maintenance (Baer, Blount, Detrich, \& Stokes, 1987; Freeland \& Noell, 1999, 2002; Goldsmith, LeBlanc, \& Sautter, 2007; Hopkins, 1968; Kazdin \& Polster, 1973; Koegel \& Rincover, 1977) and involves reinforcing only a portion of total occurrences of target behavior. Kazdin and Polster demonstrated the effect of intermittent delivery of tokens on maintained levels of social interaction during work breaks for one individual identified as having mental retardation. The results showed that the participant continued to engage in high levels of social interaction after reinforcement was withdrawn.

Another useful strategy for promoting generalization involves programming common stimuli. Stokes and Baer (1977) describe this strategy as incorporating common and salient stimuli in both the training and generalization settings. Despite the ease with which common stimuli may be programmed across settings, this generalization strategy has received less attention in the literature compared to other techniques (Stokes \& Baer, 1977).

Prior studies on programming common stimuli have examined the maintenance of responding to academic tasks (Freeland \& Noell, 1999, 2002; Mesmer, Duhon, \& Dodson, 2007). Freeland and Noell (1999) programmed a written goal, the color of the worksheet, and indiscriminable contingencies to increase and maintain the participants' digits correct on math probes. The authors found that programming delayed, intermittent reinforcement 
and common stimuli led to maintained responding on math probes for four students enrolled in a fourth-grade general-education classroom. Nevertheless, these prior studies evaluated treatment packages that included multiple components to promote maintained levels of responding beyond simply programming common stimuli. Thus, the studies by Freeland and Noell $(1999,2002)$ do not allow for a direct examination of the effects of programming common stimuli because delayed, intermittent reinforcement was simultaneously programmed during treatment. Future research might evaluate the unique contributions of programming common stimuli on maintenance of responding to determine whether this inexpensive and easy-to-use component of intervention can promote lasting behavior change.

Additional research on the maintenance of behavior in small-group settings is warranted, also. Although studies on group contingencies have examined the maintenance of target behavior (e.g., Hawkins et al., 2009), none have directly programmed for maintenance and generalization. Yet, Tier II (i.e., small-group) interventions seek to produce lasting behavior change across individuals (Rodriguez \& Anderson, 2013). Identifying ways to promote maintenance of behavior across individuals within small groups with easy-to-use modifications, like programming common stimuli, may improve the durability of interventions delivered in school-based settings. 


\section{Research Questions}

The proposed study will seek to evaluate the following research questions:

1. What is the effect of programming common stimuli and a randomized dependent group contingency on levels of academic engagement for participants receiving small-group reading and writing instruction?

i. We hypothesized that all participants will have higher levels of academic engagement during intervention than during baseline.

2. What is the effect of programming common stimuli on the maintenance of academic engagement when other components of the intervention package are withdrawn?

i. We hypothesized that we would observe maintained levels of academic engagement in the presence of the common physical stimulus.

3. What is the effect of programming common stimuli and a randomized dependent group contingency on the level of problem behavior in participants receiving small-group reading and writing instruction?

i. We hypothesized that all participants will engage in lowers levels of problem behavior during intervention than during baseline. 


\section{CHAPTER II}

\section{METHOD}

\section{Participants}

Three groups of students enrolled in the Center on Teaching and Learning's summer reading clinic participated in the current study. Each group consisted of two to three participants entering second grade who were identified as "some-risk" or "high-risk" on their spring easyCBM reading benchmarks (Alonzo \& Tindal, 2009) conducted by the district in order to participate in the reading clinic.

Participants were grouped with peers who scored similarly on easyCBM benchmarks. The reading clinic staff also used anecdotal reports of problem behavior from familiar adults to place participants in groups. That is, participants were grouped so that no more than one student engaged in high rates of off-task or problem behavior.

The participant in each group who had the lowest mean level of academic engagement during baseline was our "primary participant." The other participants in the group were referred to as "secondary participants." The primary participant's data informed phase changes, with the secondary participants' data showing concomitant changes in behavior.

\section{Setting}

All sessions were conducted in two classrooms at a local, community school. Each group of participants sat facing the instructor at one of four semi-circular tables present in a room. All participants were seated within $1 \mathrm{~m}$ of the instructor with relevant materials placed directly in front of them. An instructor and data collector were present during all sessions and seated within $2 \mathrm{~m}$ of each other. A second data collector was 
present during at least $33 \%$ of sessions for each group. Reading clinic and University of Oregon supervisors periodically observed instruction, too. All small groups received instruction for two hours per day, four days a week.

\section{Materials}

Each instructor received materials associated with both the Read Well I and Write Well curricula. These materials included participant booklets, read-along books, flash cards, and miscellaneous items associated with lessons (e.g., slinky for blending sounds). Intervention materials included a laminated $29.7 \mathrm{~cm} \mathrm{x} 21 \mathrm{~cm}$ piece of yellow paper with a number printed on it in size 400 Times New Roman black font, a bag for drawing preferred items, preferred items based on participants' selections during a preference assessment, a clipboard, an application for smart phones that uses a tactile prompt for time intervals through vibration, and data sheets (Appendix A).

\section{Experimental Design}

An $\mathrm{ABABC}$ reversal design was used to evaluate the effects of treatment and programming common stimuli on academic engagement, problem behavior, and maintenance of responding. Phase A was the baseline phase in which we measured the level of academic engagement and occurrence of problem behavior when no intervention was in place. In Phase B, which was the treatment phase, we evaluated the effects of programming common stimuli and a randomized dependent group contingency on the participants' levels of academic engagement and problem behavior. The treatment phase was followed by a second Phase A, in which we withdrew treatment in order to demonstrate that changes in the levels of academic engagement and occurrence of problem behavior were due to the treatment package. We then implemented the treatment 
phase again (i.e., Phase B), followed by Phase C, which was the maintenance phase.

Phase $\mathrm{C}$ included the previously programmed common stimuli without the randomized dependent group contingency, which allowed for an evaluation of maintenance of behavior change.

\section{Measurement}

Dependent variables. Our primary dependent variable was academic engagement, which was defined as the presence of the following behaviors: (a) appropriate vocal behavior, (b) remaining seated, and (c) appropriate looking. Appropriate vocal behavior was defined as the participant engaging in a vocal response only when called upon or presented with a choral-response opportunity. Appropriate vocal behavior also was scored if the participant was sitting quietly (i.e., no vocal behavior that could be heard from more than $3 \mathrm{ft}$ away) while the instructor or other participants were speaking. Remaining seated was scored if the participant's bottom was on or within $5 \mathrm{~cm}$ of the chair seat. Appropriate looking was defined as the participant's eyes oriented toward the instructor or instructional materials.

Observers collected data on academic engagement using a 30-s momentary-timesampling (MTS) procedure. The MTS method of data collection is recommended when measuring behavior that occurs for longer durations of time (Powell, Martindale, \& Kulp, 1975; Powell, Martindale, Kulp, Martindale, \& Bauman, 1977). Data collection occurred out of view of the participants (e.g., on the data collector's clipboard) to reduce participant reactivity to the presence of data collection and data sheets.

Data collectors also measured the frequency of problem behavior during each session. Problem behavior included disruption and negative vocalizations. Disruption was 
defined as the participant touching instructional materials that were not a part of the current task, closing the book when the task included the use of the book, touching other participants' materials, or throwing items onto the floor. Negative vocalizations were defined as any vocalization above conversational level (e.g., shouting, screaming), crying, swearing, or complaints about activities (e.g., "I don't want to read anymore." or "This is too hard."').

Rates of problem behavior were compared across phases to determine the effect of programming common stimuli and a randomized dependent group contingency on behavior that was not captured by the academic engagement definition nor was part of the requirement for reinforcement. The frequency of problem behavior in each session was converted to a rate by dividing the total occurrences of problem behavior by the number of minutes in the session.

We also obtained measures of participant performance on easyCBM probes before and after participation in the summer reading clinic. Word Reading Fluency (WRF) and Passage Reading Fluency (PRF; Alonzo \& Tindal, 2012) progress monitoring measures were conducted by trained reading clinic staff during the first session and the last week of the summer reading clinic. All students were delivered the same probe from spring of first grade during the first session and fall of second grade during the final week.

Passage Reading Fluency is a measure of students' oral reading fluency (Alonzo, Park, \& Tindal, 2013). During the PRF probes, participants were given a narrative passage containing approximately 250 words and instructed to read it aloud. The administrator began timing once the participant read the first word and stopped the participant after $1 \mathrm{~min}$. Errors and omitted words were crossed out in the examiner's 
booklet and subtracted from the total number of words in order to identify the total correct words.

A WRF probe was administered to each participant. This probe measured the participant's mastery of decoding and sight-word reading, which are measures of oral reading fluency (Alonzo, Park, \& Tindal, 2013). The assessor presented the participant with a page of words (Alonzo \& Tindal, 2012) printed on a $21 \mathrm{~cm}$ x $29.7 \mathrm{~cm}$ piece of paper and presented one row of words at a time while covering the remaining rows. The duration of this probe was $1 \mathrm{~min}$. Errors were subtracted from the total number of words read to identify the total correct words.

Independent variables. The independent variables in the proposed study included the presence of a common stimulus, the implementation of a randomized dependent group contingency, and frequency of praise. The introduction and removal of these independent variables was manipulated across phases for each participant.

The common stimulus included in treatment and maintenance phases was a yellow paper with a number written on it (see Materials section). During treatment, the presence of this paper with a number on it was paired with the availability of reinforcement in the form of a break and access to a tangible item contingent on a specified amount of academic engagement during each session

The randomized dependent group contingency included multiple intervention components that were randomly selected if one of the participants within the small group met the reinforcement criterion. We randomized the selection of one participant whose behavior informed the group's access to the reinforcement interval for each session. If the selected participant's behavior met the established behavioral criterion written on the 
yellow paper during intervention, the data collector signaled to the instructor who stopped instruction and told the participants that the group earned a break based on that participant's behavior. The instructor presented a bag that contained slips of paper with each participant's most-preferred items written on them. The instructor then selected a slip of paper from the bag, and the participants were given access to that item or activity for 1 min during their break. For example, if the instructor selected a block assembly toy, then each participant received a block assembly toy kit to play with during the 1-min break.

The total number of praise statements by the instructor were manipulated during each phase. Praise was defined as any statement by the instructor regarding student performance or behavior, stated in a positive way, that was two words or greater (e.g., "good job," "excellent reading," "I like how your feet are on the ground"). Non-examples of praise statements included "good" or "right," and were delivered to indicate performance on independent and group reading opportunities.

Interobserver agreement and fidelity of implementation. Each independent observer was trained on the research protocol, dependent variables, and the datacollection procedure prior to the summer reading clinic. To collect data during study sessions, all observers demonstrated at least $80 \%$ agreement across two consecutive sessions using the interval-by-interval method of IOA (Repp, Deitz, Boles, Deitz, \& Repp, 1976). Data collectors practiced taking data and demonstrated reliable data collection using a 10-min video prepared and scored by the primary investigator. This video included examples and non-examples of academic engagement and problem behavior. 
One observer collected data on all dependent variables during $100 \%$ of sessions across conditions. A second independent observer collected data during $66.3 \%, 88.3 \%$, and $67.2 \%$ of sessions for groups $1-3$, respectively. We calculated IOA for academic engagement using the interval-by-interval method. That is, data in each response interval was scored as either an agreement or disagreement. The number of intervals with an agreement was divided by the total number of intervals in the session, and the ratio was converted to a percentage. Mean interval-by-interval agreement was $92.6 \%$ (range, $83.3 \%$ to $100 \%$ ) for group $1,93.0 \%$ (range, $81.7 \%$ to $100 \%$ ) for group 2 , and $96.5 \%$ (range, $85 \%$ to $100 \%$ ) for group 3 . Total IOA was calculated for problem behavior by dividing the smaller number of observed responses by the larger number of observed responses and multiplying by 100 (Rolider, Iwata, \& Bullock, 2012). Mean IOA for problem behavior was $93.1 \%$ (range, $0 \%$ to $100 \%$ ) for group $1,96.2 \%$ (range, $0 \%$ to $100 \%$ ) for group 2, and $96.6 \%$ (range, $0 \%$ to $100 \%$ ) for group 3 . IOA was $0 \%$ during five total sessions across all groups. Sessions with $0 \%$ IOA only occurred when an observer recorded one instance of problem behavior and the other did not observe any instances of problem behavior.

The primary investigator trained instructors to implement intervention procedures using behavioral skills training (e.g., Johnson, Miltenberger, Egemo-Helm, Jostad, Flessner, \& Gatheridge, 2005; Miltenberger, Flessner, Gatheridge, Johnson, Satterlund, \& Egemo, 2004; Sarokoff \& Sturmey, 2004). This training included instruction, modeling, rehearsal, and feedback as described by Sarokoff and Sturmey (2004). Instructors received a written copy of the intervention procedures and operational definitions, and the instructors and primary investigator reviewed each component of intervention 
together. During modeling, the primary investigator demonstrated the delivery of the opening script (i.e., introducing the goal/yellow paper), providing praise, and the procedures associated with the randomized dependent group contingency. During rehearsal, the instructors engaged in the previously modeled behavior (i.e., delivering the opening script, providing praise, and the randomized group contingency procedures). Instructors received descriptive verbal feedback during the rehearsal portion of training. Instructors were required to deliver the opening script, provide praise, and implement the procedures for the randomized dependent group contingency during a one-on-one assessment with a trainer with $100 \%$ fidelity on all components. All instructors met this criterion during the first session.

The instructors also received training on how to respond to problem behavior. Instructors were trained to refrain from commenting on problem behavior, provide praise when the participant engaged in appropriate behavior, continue to deliver instructional content, and continue to present opportunities for the student to respond. During behavioral skills training, the primary investigator modeled how to respond to problem behavior and provided the instructors with practice opportunities and feedback on this content.

The instructor's fidelity of implementation during sessions was calculated to evaluate adherence to the research protocols. Fidelity measures were based on the instructor delivering praise on the appropriate schedule, delivering reinforcement according to the predetermined goal, implementing the randomization procedures for selecting a participant and reinforcer, and responding to problem behavior appropriately. At the end of every day, a fidelity of implementation checklist (Appendix B) was 
completed by the instructor and independent observer. If two consecutive days were found to be below $80 \%$ adherence, as identified by either the instructor or independent observer, the instructor was retrained on the sections of the research protocol that were not implemented with fidelity. We found that instructors consistently implemented the procedures with fidelity with no sessions implemented below $80 \%$ across all groups. On average, instructors completed $96.3 \%$ (range, $80 \%$ to $100 \%$ ) of components with fidelity.

\section{Preference Assessment}

A multiple-stimulus without replacement (MSWO; DeLeon \& Iwata, 1996) preference assessment was conducted with each participant in the group prior to the first small-group session (see Appendix C). Items were included in the MSWO from a predetermined list of tangible items. All items were equally spaced in a horizontal array in front of the participant. The experimenter waited for the student to look at all of the items, and instructed the participant to select one item. After an item was chosen, the participant was given $20 \mathrm{~s}$ of access to the selected item. The chosen item was then removed from the array, and the experimenter rotated the remaining items by placing the item on the left end on the far right of the horizontal array. This procedure was repeated until all items were selected.

The MSWO was repeated until one of the criteria outlined by Layer, Hanley, Heal, and Tiger (2008) were met, including: (a) an item was chosen as most preferred four times consecutively, (b) an item was selected as most preferred four more times than any other item, or (c) two items were selected the same number of times and four more times than any other item. Each participant's most-preferred item was included as a potential toy to be selected during the reinforcement interval. To ensure that more than one item 
could potentially be selected during the reinforcement interval, if all participants in a group selected the same item, the next highest preferred item across all participants was included.

\section{Contingency Space Analysis}

To develop hypotheses regarding the potential function of the participant's problem and off-task behavior, the primary investigator evaluated data collected on the first day of the reading clinic to generate a separate contingency space analysis (CSA; Martens, DiGennaro, Reed, Szczech, \& Rosenthal, 2008) for each behavior (i.e., problem behavior and off-task behavior) and each participant. During sessions on the first day of reading clinic, trained observers recorded all occurrences of problem and off-task behavior and the consequences following the behavior (i.e., a break, adult attention, and peer attention). Observers also collected data on consequences that occurred in the absence of the target behavior. Consequences were recorded as co-occurring with an instance of behavior if they occurred within $5 \mathrm{~s}$ of problem or off-task behavior. Consequences were recorded as occurring in the absence of the target behavior if they did not occur within $5 \mathrm{~s}$ of problem or off-task behavior.

The probability of a consequence following problem or off-task behavior, and in the absence of problem or off-task behavior, was graphed using a CSA (Martens, DiGennaro, Reed, Szczech, \& Rosenthal, 2008). We calculated the probability of a consequence following problem or off-task behavior by taking the number of occurrences of the behavior prior to a consequence (e.g., attention) divided by the total number of problem or off-task behavior observed. For example, if the participant engaged in problem behavior five times, and attention followed three instances of problem behavior, 
the probability of receiving attention for problem behavior was 0.60 (i.e., 3 instances of problem behavior and attention $/ 5$ instances of problem behavior). The probability of a consequence occurring in the absence of problem or off-task behavior was calculated by taking the number of intervals in which the consequences occurred in the absence of problem or off-task behavior divided by the number of intervals with the absence of problem or off-task behavior. Appendix D shows an example of a CSA data sheet. Probabilities of at least 0.50 were considered potential functions for problem or off-task behavior.

\section{Procedure}

Small groups received instruction four times a week for approximately two hours per day. The first hour consisted of reading instruction using the Read Well I curriculum, followed by a brief break, with spelling instruction using the Write Well curriculum implemented for the remaining time. If all of the Read Well I content was not covered within the first hour, the instructors continued reading instruction after the break until all components were completed. The instructors implemented intervention during all instructional time.

On the first day of the reading clinic, participants received instruction in the reading clinic expectations: (a) sit square in your chair, (b) follow directions, and (c) do your best reading. Examples and non-examples were provided for each rule, and participants were guided to practice the correct way of following each rule. These rules were posted and reviewed at the beginning of every day. 
Sessions consisted of 10-min periods. On average, six sessions were conducted each day (range, 3 to 8 ). The first session and data collection began after the instructor reviewed the reading clinic rules with the participants.

Baseline. No programmed stimuli (i.e., no point card or goal) were present during sessions, and no tangible or edibles were provided during this phase. Instructors delivered verbal praise contingent on appropriate participant behavior (e.g., reading) less than five times during each 10-min session. The instructor began the day by saying, "There's no goal for today, so we won't be able to earn any rewards or breaks."

Training. Following baseline, but immediately prior to the introduction of the intervention, the instructor introduced and provided an example of treatment. The instructor presented the yellow paper with the number 1 written on the front and said, "I will randomly pick someone in our group. If I see the student following the rules one time, I will choose an item out of this bag and all of you will get to play with it. You won't know who has to follow the rules to earn the reward, so you should all try your best."

The instructor introduced the method of selecting preferred items during training. Specifically, the instructor told the group that every participant's favorite item was written on a piece of paper and placed in the bag. If a participant's behavior met the goal written on the yellow paper, the instructor drew a piece of paper out of the bag and everyone was able to play with the chosen item.

The instructor provided an intervention training opportunity during reading instruction with participants. An observer collected data on academic engagement for one participant using the 30-s MTS interval for 1 min. Thereafter, the instructor said, "Now 
let's see if you earned a chance to choose an item out of the bag." If the randomly selected participant was academically engaged during at least one interval within the 1min data-collection period, the instructor said, "(Participant's name) was following the rules! Now I can pick an item out of this bag." The instructor then selected an item from the bag, and the participants had $1 \mathrm{~min}$ to play with the selected item during their break. If the participant was not following the rules, the instructor said, "The student's whose name I picked was not following the rules. Let's keep working so you will have another chance to earn an item from the bag." However, this was unnecessary because all groups met the criterion during the first training session.

Treatment. A yellow paper with a number written in the middle of the page was placed on the table in view of all the participants. The instructor held the paper in front of the participants and said, "This is your goal for today." The goal was based on the level of academic engagement required to obtain reinforcement (i.e., a goal of 8 corresponds to $80 \%$ of intervals with academic engagement).

The initial goal was selected based on the mean level of academic engagement during baseline for the primary participant. For example, if the primary participant's mean level of academic engagement during baseline was $50 \%$, the initial goal during intervention was 5 (or $50 \%$ of intervals). The initial goal during treatment was 5,6 , and 7 for groups 1-3, respectively. If the primary participant's level of academic engagement was at or above the criterion for a single session, the criterion was increased by $10 \%$ until the goal reached $80 \%$. Once the goal reached $80 \%$, it remained at that criterion throughout the remainder of treatment. 
The instructor delivered verbal praise to the participants for appropriate behavior more than 15 times per session. At the end of each session, the data collector identified whether the selected participant met the criterion for reinforcement and discretely provided this information to the instructor (i.e., a plus or minus on a clipboard that was out-of-view of the participants). If the selected participant's academic engagement was at or above the criterion level, the instructor said, “(Participant's name) followed the rules! Now let's see what you will get to have during your break." The instructor selected a slip of paper from the bag, read the item on the slip of paper, and gave the participants the item to consume for $1 \mathrm{~min}$. If the selected participant's behavior did not reach the predetermined criterion, the instructor did not acknowledge the missed goal and immediately initiated the next session.

Maintenance. The procedures were identical to baseline with a few exceptions. The instructor placed the yellow card with a goal written on it in view of all participants and said, "This is your goal for today." At the end of each session, the instructor did not provide information about whether the participants met their goal and did not deliver reinforcement. In addition, the instructor did not draw any slips of paper from the bag at the conclusion of each session.

\section{Social Validity}

The Treatment Evaluation Inventory- Short Form (TEI-SF; Kelley, Heffer, Gresham, \& Elliott, 1989) was given to all instructors at the end of the study in order to assess treatment acceptability (Appendix E). This form included nine items that were rated on a 5-point Likert-type scale ( $1=$ strongly disagree; $5=$ strongly agree $)$. An example item was "I like the procedures used in this treatment" (Kelley, Heffer, Gresham, 
\& Elliott, 1989). The short form of this measure was chosen, as prior findings have indicated that the TEI-SF is more preferred and takes less time than the TEI (Finn \& Sladeczek, 2001).

\section{Data Analysis}

We used visual analysis (Horner, Carr, Halle, McGee, Odom, \& Wolery, 2005) to evaluate differences between conditions. In addition, decision rules were used to inform the progression of phases.

During baseline phases, we conducted a minimum of five sessions with all groups. Groups did not progress into the treatment phase until the primary participant's behavior in the final three data points was stable or decreasing and there was less than $30 \%$ variability between these points. The baseline phase continued until these criteria were met.

We collected at least 5 sessions of data during each treatment phase. The primary participant's data must have had less than $20 \%$ variability for three consecutive sessions, at least a $10 \%$ increase in the mean level of academic engagement above baseline levels, and a stable or increasing trend for three consecutive sessions before we introduced the second baseline condition or implemented the maintenance phase.

During the maintenance phase, sessions continued until a decreasing trend was observed for five consecutive sessions with the mean level of academic engagement at least $20 \%$ below the mean level of academic engagement in treatment. Academic engagement was said to have "maintained" if the above criteria were not met after 10 sessions. This criterion for maintenance aligns with the criterion used by Koegel and Rincover (1977). In an effort to use more rigorous standards for maintenance than in 
prior research, we continued to conduct this phase for, on average, 35 sessions (range, 20 to 57) with all groups. 


\section{CHAPTER III}

\section{RESULTS}

The effect of randomized dependent group contingencies and programming common stimuli on academic engagement, rate of problem behavior, and durability of responding are shown for groups 1-3 in Appendix G, H, and I, respectively. Data for primary participants are presented in the top panel, with data for secondary participants in the remaining panels.

\section{Group 1}

During baseline, the primary participant engaged in low levels of academic engagement with no problem behavior (Figure 1, top panel). Participants 2 and 3 had higher levels of academic engagement, relative to the primary participant, with no occurrences of problem behavior (Figure 1, middle and bottom panels). Participant 3 had variable levels of academic engagement ranging from $45 \%$ to $90 \%$ of intervals (Figure 1 , bottom panel).

During treatment, the primary participant had an initial decrease in academic engagement, followed by an increasing trend in behavior. The final nine sessions of the primary participant's treatment showed that academic engagement was at or above $80 \%$. Nevertheless, the primary participant engaged in low rates of problem behavior during some of the treatment sessions near the end of the phase. Secondary participants had levels of academic engagement that remained high during treatment. Participant 3 had a higher mean level of academic engagement for the final five data points in this phase in comparison to mean levels of academic engagement in baseline. No problem behavior was observed during the first treatment phase for the secondary participants. 


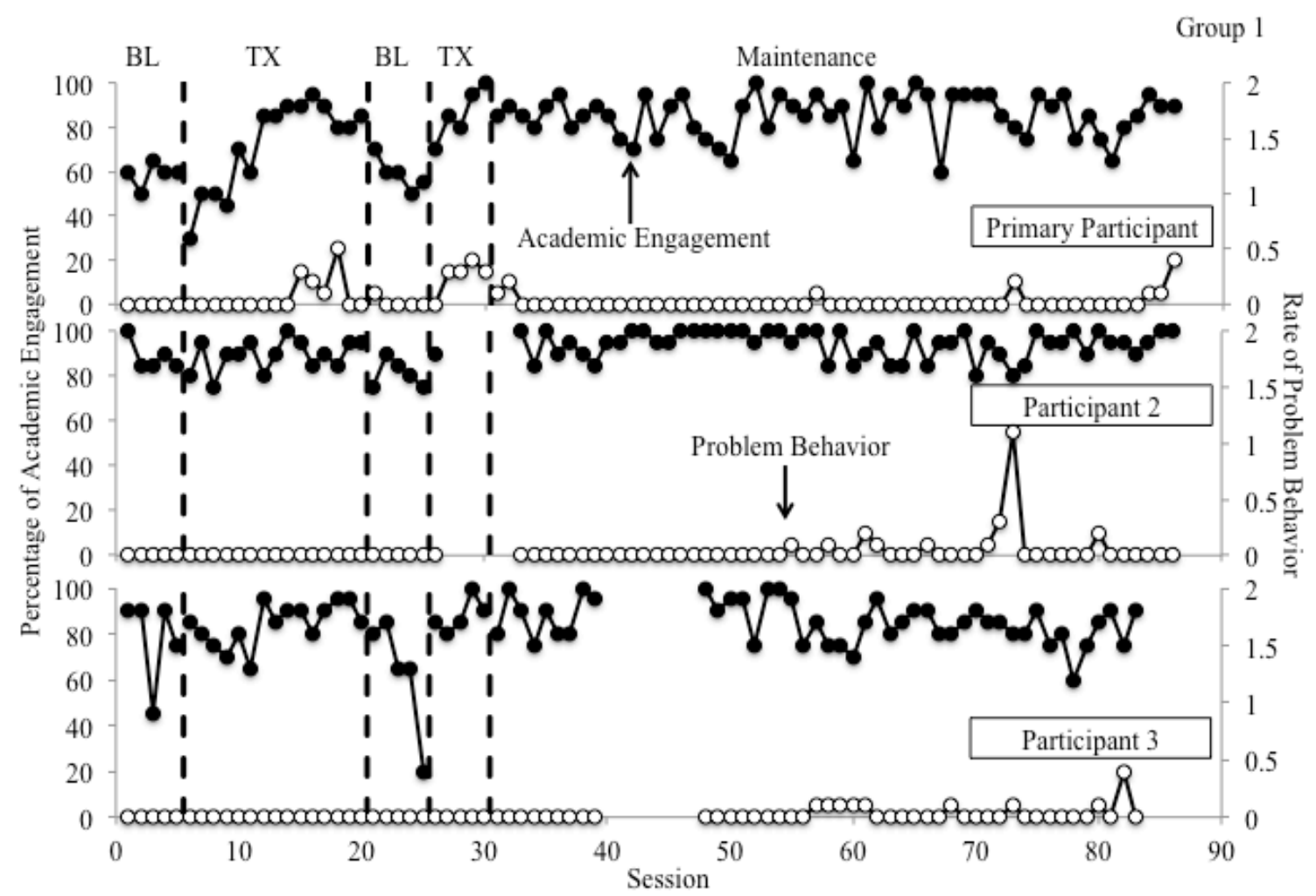

Figure 1. Percentage of session with academic engagement and problem behavior for group 1.

During the second baseline phase, level of academic engagement decreased for all participants. A decreasing trend in academic engagement was observed for the primary participant and participant 3, with final percentages of academic engagement at $55 \%$ and $20 \%$ for these participants, respectively. The primary participant engaged in one instance of problem behavior during baseline.

Treatment was then reintroduced, and academic engagement increased to levels similar to those in the prior treatment phase for the primary participant and participant 3. Participant 2 was only present for a single session during this phase due to absences. As observed during the initial treatment phase, the primary participant engaged in low rates of problem behavior. 
Moderate to high levels of academic engagement were observed across all participants during the maintenance phase. Problem behavior was also observed at a low rate across all participants with the highest rate of problem behavior observed during one session of maintenance for participant 2. Academic engagement maintained until the completion of the summer reading clinic program. That is, moderate to high levels of academic engagement continued for 55 sessions in the absence of treatment without meeting the termination criteria.

\section{Group 2}

The primary participant's academic engagement had a decreasing trend throughout baseline (Figure 2, top panel). The final session of baseline showed that the primary participant was academically engaged during only $30 \%$ of intervals. The percentage of academic engagement was relatively high for participants 2 and 3 (Figure 2, middle and bottom panels). The primary participant engaged in problem behavior once during baseline.

After introducing treatment, we observed an increasing trend in academic engagement for the primary participant and participant 3. During the last three sessions of treatment, the primary participant was academically engaged during $90 \%$ of intervals. Participant 2 continued to engage in high levels of academic engagement throughout treatment. We observed low levels of problem behavior during the last treatment sessions for the primary participant and participant 3. 


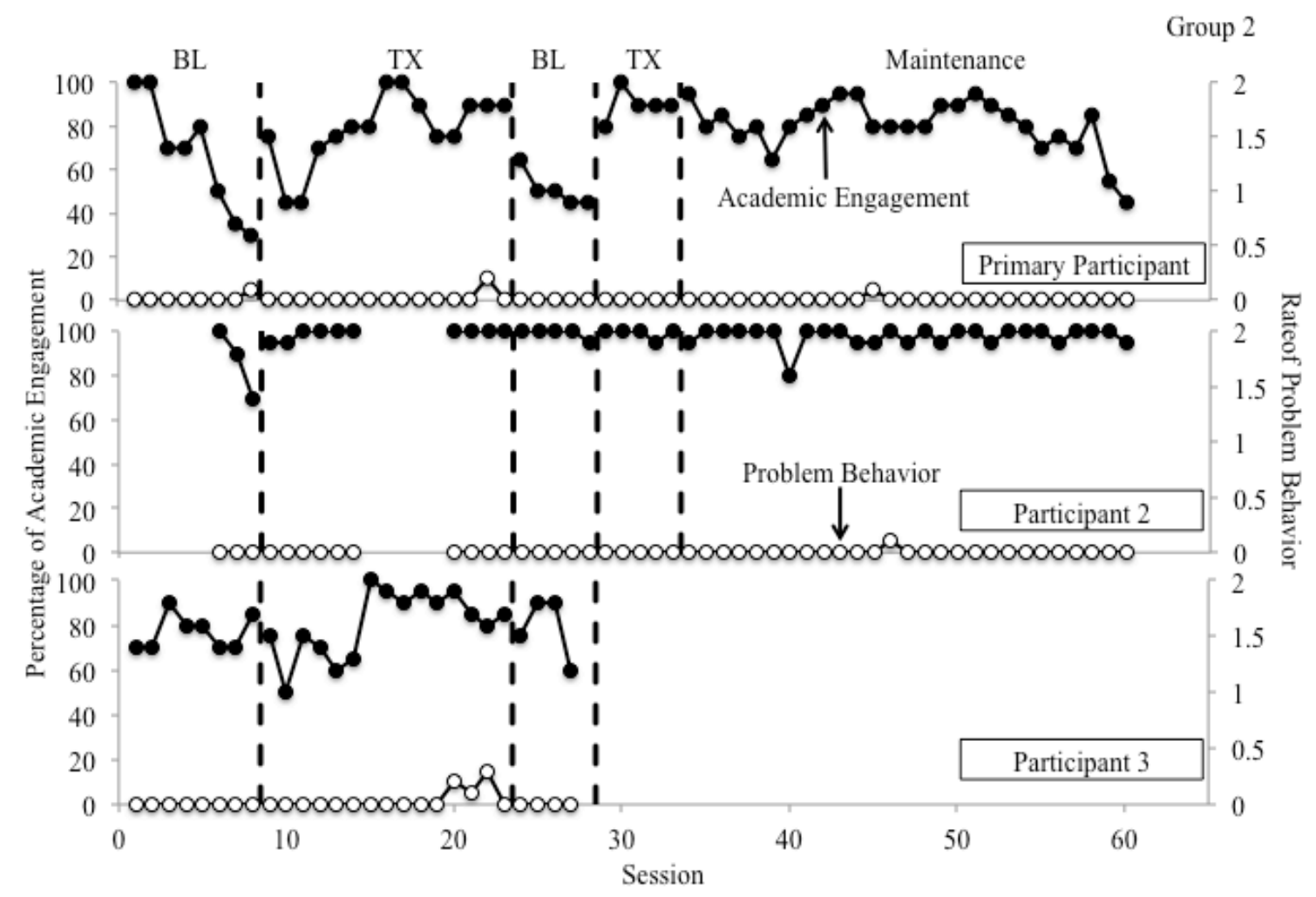

Figure 2. Percentage of session with academic engagement and problem behavior for group 2.

Baseline sessions were reintroduced, and we observed an immediate decrease in the level of academic engagement and a decreasing trend throughout baseline for the primary participant. Continued high levels of academic engagement were observed for participant 2. Participant 3 had levels of academic engagement that were variable and similar to treatment. None of the participants engaged in problem behavior during baseline. Participant 3 withdrew from the reading clinic prior to the last session of baseline.

Following the reversal to treatment, the primary participant showed an immediate increase in the level of academic engagement, which was at or above $80 \%$ for all sessions. Participant 2 continued to engage in high levels of academic engagement throughout this phase. Neither participant engaged in problem behavior during treatment. 
The primary participant had variable and moderate to high levels of academic engagement during the maintenance phase. However, we observed a decreasing trend in academic engagement during the last 10 sessions. Despite meeting our maintenance criterion of ten sessions, we continued in this phase until the primary participant met the termination criterion after 27 sessions. Participant 2 continued to engage in high levels of academic engagement throughout the maintenance phase. Each participant engaged in problem behavior during one maintenance session.

\section{Group 3}

The final group included two participants. During baseline, a decreasing trend in academic engagement and an increasing trend in problem behavior was observed across both participants. Both participants engaged in moderate rates of problem behavior during the final three sessions of baseline (Figure 3).

Both participants had an immediate increase in levels of academic engagement during treatment. The primary participant was academically engaged during $90 \%$ or more of intervals in all treatment sessions (Figure 3, top panel). Participant 2 had levels of academic engagement that were at or above $80 \%$ during all treatment sessions (Figure 3, bottom panel). We observed low levels of problem behavior during treatment for both participants.

Following the reversal to baseline, the primary participant had continually high levels of academic engagement for 14 sessions. Thereafter, we observed a decreasing trend in academic engagement that replicated the levels observed in the initial baseline. Participant 2 had variable levels of academic engagement that were at or slightly below the levels observed during treatment. However, the last four sessions of baseline were 
low and comparable to the levels of academic engagement observed during the initial baseline. Variable levels of problem behavior were observed across both participants.

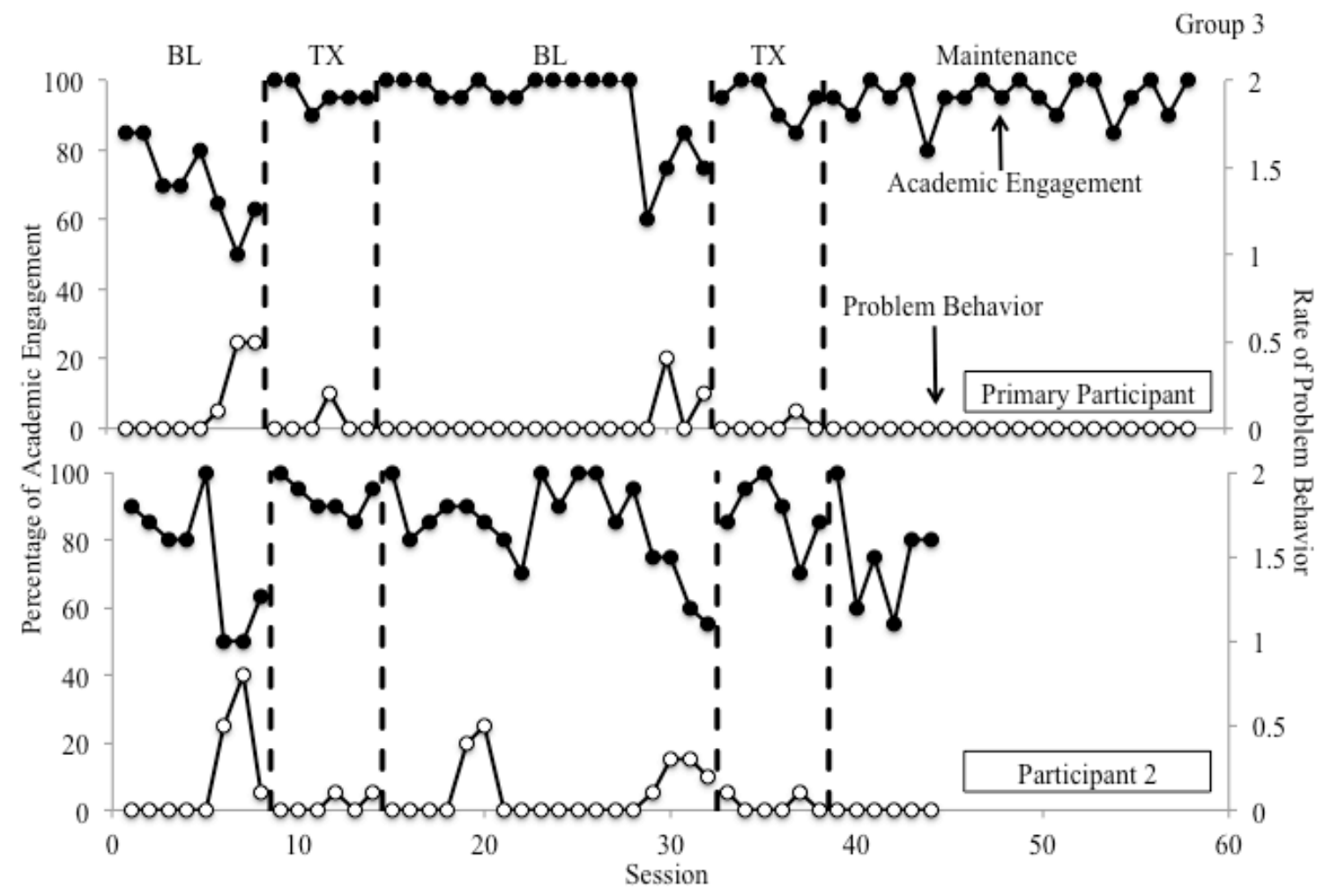

Figure 3. Percentage of session with academic engagement and problem behavior for group 3.

The immediate increase in the level of academic engagement when treatment was reintroduced replicated the effect of treatment on academic engagement. That is, both participants had levels of academic engagement in the first session of treatment that were at least $20 \%$ higher than the previous baseline session. The primary participant was academically engagement during at least $80 \%$ of intervals in all treatment sessions. Participant 2 had variable levels of academic engagement, although academic engagement was at or above $80 \%$ for five out of the six treatment sessions. Both participants engaged in low levels of problem behavior during treatment. 
During the maintenance phase, the primary participant continued to engage in high levels of academic engagement that were similar to the levels of behavior observed during treatment. High levels of academic engagement maintained for 20 sessions, after which the summer reading program ended. Participant 2 had variable levels of academic engagement that were comparable to baseline during some sessions. Participant 2 discontinued participation in the reading clinic after six sessions in the maintenance phase. No problem behavior was observed during the maintenance phase.

\section{Contingency Space Analysis}

A contingency space analysis was conducted on the first day of the reading clinic. We examined the probability of consequences (i.e., peer attention, adult attention, and escape) following problem or off-task behavior. We also examined the probability that the consequence was delivered in the absence of problem and off-task behavior. No occurrences of problem behavior were observed for participants in group 1 or 2 . For group 1, escape followed off-task behavior during $100 \%$ of occurrences for the primary participant (62 total occurrences), 100\% for participant 2 (29 total occurrences), and 95\% for participant 3 (61 total occurrences). For group 2, the primary participant engaged in off-task behavior one time, which was immediately followed by escape. Participant 2 engaged in 16 instances of off-task behavior, which produced escape during 94\% of occurrences. Participant 3 was absent on the first day of the reading clinic so we were unable to calculate conditional probabilities for this participant's behavior. The primary participant in group 3 engaged in three instances of problem behavior which produced escape during $67 \%$ of occurrences. The secondary participant engaged in two instances of problem behavior, which led to escape during one trial (i.e., $50 \%$ of occurrences). The 
primary participant also engaged in 22 instances of off-task behavior, which produced escape 21 times (i.e., $95 \%$ of occurrences). Participant 2 engaged in off-task behavior eight times during the observation, which produced escape five times (i.e., $63 \%$ of occurrences).

Adult attention was delivered more frequently in the absence of off-task behavior for groups 1 and 2. In group 3, adult attention was available at a similar rate following an occurrence of off-task or problem behavior and in the absence of these behaviors. Peer attention as a consequence was observed four times in group 1 and five times in group 3 . Peer attention followed one occurrence of off-task behavior by participant 2 in group 3 . Thus, adult and peer attention was not readily available as a consequence following occurrences of problem or off-task behavior.

We concluded that the probability of escape following an occurrence of off-task behavior was higher than escape that occurred in the absence of this behavior. Consistent with the high proportion of consequences criterion set by Martens et al. (2008; i.e., .50), we found that the function of off-task behavior was escape for five participants. However, two participants engaged in low rates of off-task behavior. For example, escape was delivered following the only occurrence of off-task behavior by the primary participant in group 2 (i.e., $100 \%$ of occurrences) and following two of three total occurrences of offtask behavior by participant 2 in group 3 (i.e., $67 \%$ of occurrences). Similarly, problem behavior was only observed by participants in group 3 during our observations, and the frequency of problem behavior was low (i.e., 5 total occurrences). Thus, the function of off-task and problem behavior for the three participants with very low rates of problem and off-task behavior should be interpreted with caution. 


\section{Reading Measures}

Progress monitoring PRF and WRF probes were conducted during the first session and last week of the reading clinic. Due to attrition, one participant's data were excluded. Participant performance on the PRF probe at pre-intervention was, on average, 39.0 total correct words (range, 11 to 66 ). The pre-intervention progress-monitoring probe was drawn from materials for students enrolled in first grade in spring. The postintervention progress-monitoring probe included an assessment for students in the fall of second grade. Post-intervention average performance was 30.4 total correct words (range, 12 to 49). Average performance on the WRF probe was 30.1 total correct words (range, 14 to 42 ) during pre-intervention and 26.7 total correct words (range, 14 to 36) during post-intervention. Thus, both probes showed reductions in total correct words in the postintervention probes.

\section{Social Validity}

Instructor responses on the TEI-SF indicate an overall positive response to the treatment package with the mean and range for each item shown in Table 1. Instructors strongly-agreed that they would be willing to use the procedure to change child behavior $(M=4.67$; range 4 to 5$)$, they had a positive reaction to the treatment $(M=4.67 ;$ range 4 to 5), it would be acceptable to use this procedure without the child's consent $(M=4.67$; range 3 to 5), and strongly-disagreed that the child would experience discomfort during this treatment $(M=1.17$; range 1 to 2$)$. 
Table 1

Mean and range of instructor ratings on Treatment Evaluation Inventory-Short Form (TEI-SF)

\begin{tabular}{|c|c|c|}
\hline Item & $M$ & Range \\
\hline $\begin{array}{l}\text { I find this treatment to be an acceptable way of dealing with the } \\
\text { child's behavior. }\end{array}$ & 4.50 & $4-5$ \\
\hline $\begin{array}{l}\text { I would be willing to use this procedure if I had to change the } \\
\text { child's behavior. }\end{array}$ & 4.67 & $4-5$ \\
\hline $\begin{array}{l}\text { I believe that it would be acceptable to use this treatment without } \\
\text { children's consent. }\end{array}$ & 4.67 & $4-5$ \\
\hline I like the procedures used in this treatment. & 4.33 & $4-5$ \\
\hline I believe this treatment is likely to be effective. & 4.33 & $3-5$ \\
\hline $\begin{array}{l}\text { I believe the child will experience discomfort during the } \\
\text { treatment. }\end{array}$ & 1.17 & $1-2$ \\
\hline $\begin{array}{l}\text { I believe this treatment is likely to result in permanent } \\
\text { improvement. }\end{array}$ & 3.00 & $2-5$ \\
\hline $\begin{array}{l}\text { I believe it would be acceptable to use this treatment with } \\
\text { individuals who cannot choose treatments themselves. }\end{array}$ & 4.67 & $3-5$ \\
\hline Overall, I have a positive reaction to this treatment. & 4.67 & $4-5$ \\
\hline
\end{tabular}




\section{CHAPTER IV}

\section{DISCUSSION}

We evaluated the effect of a dependent group contingency and programming common stimuli on the level and maintenance of academic engagement and problem behavior in students receiving small-group reading and writing instruction. Our findings showed that the dependent group contingency was associated with higher levels of academic engagement across the primary participants. The effects of treatment also were observed for three secondary participants, and two secondary participants engaged in high levels of academic engagement across all phases. Level of academic engagement maintained across groups 1 and 2 in the presence of the programmed common stimuli when the treatment package was withdrawn. The primary participant in group 3 continued to engage in high levels of academic engagement during maintenance; however, participant 2 engaged in variable levels of academic engagement during maintenance before withdrawing from the reading clinic. Only group 2 met the criterion to terminate the maintenance phase after 27 sessions. Groups 1 and 3 never met the termination criterion and continued in the maintenance phase for 57 and 20 sessions, respectively, until the completion of the summer reading clinic. Finally, rates of problem behavior were low across phases, with inconsistent levels of problem behavior observed across groups.

\section{Summary of Findings}

The current study evaluated a treatment package (e.g., dependent group contingency, programmed common stimuli) that was implemented during reading and writing instruction. The Read Well I and Write Well curricula are based on the principles 
of Direct Instruction (DI). Some components of DI, such as prompting, choral responding, and quick pacing, may promote higher levels of academic engagement during academic instruction (Watkins \& Slocum, 2004). Despite the potential advantages of DI on academic engagement, the dependent group contingency and common stimuli were associated with increased levels of academic engagement compared to DI alone (i.e., baseline). Thus, our results suggest that DI can be enhanced by including additional behavioral interventions that target academic engagement during instruction.

Dependent group contingencies. Consistent with prior research, we found that programming a randomized dependent group contingency promoted higher levels of academic engagement compared to baseline. This study is the first to examine the use of a dependent group contingency with second-grade students during small-group reading and writing instruction. Previous research has evaluated the effect of dependent group contingencies on student on-task behavior during third- and fourth-grade whole-class math instruction (e.g., Heering \& Wilder, 2006), rate of positive and negative statements by middle-school students with emotional disturbance (e.g., Hansen \& Lugnugaris-Kraft, 2005; Vidoni \& Ward, 2006) on-task behavior during whole-class English instruction for tenth-grade students enrolled in special education (e.g., Williamson et al., 2009), and the disruptive behavior of 17-year-old male students enrolled in a self-contained special education classroom (e.g., Theodore et al., 2004). For example, Heering and Wilder (2006) used a dependent group contingency during whole-class math instruction to increase the on-task behavior of all students in third- and fourth-grade general education classrooms. They sampled behavior by rows of students about every $12 \mathrm{~min}$. The authors found that students in both classrooms had a higher percentage of on-task behavior 
during the implementation of the dependent group contingency compared to baseline. Follow-up and social validity data indicated that the instructors continued to implement the procedures and that the intervention did not require additional time or work. However, Heering and Wilder did not describe the curriculum used or other interventions that may have been present in the classrooms.

Our results demonstrated the effectiveness of a dependent group contingency on academic engagement during small-group instruction. Similar to Heering and Wilder (2006), we found that a dependent group contingency led to higher levels of appropriate student behavior and that instructors provided favorable social validity ratings of the effectiveness and utility of the dependent group contingency.

Prior research on group contingencies has focused on evaluations of interdependent and independent contingencies. Davis and Blankenship (1996) suggest that these other types of group contingencies may be used more frequently because of the instructors' fear of social repercussions that may occur if the target participant is identified during dependent group contingencies. Although this is a possibility, it is also feasible to incorporate randomized group contingencies to reduce the likelihood of these social consequences.

The potential for group contingencies, specifically randomized dependent group contingencies, to be applied in larger systems is an important area future area of research. Applications of dependent group contingencies across systems may align with current initiatives in School-Wide Positive Behavior Support (SWPBS; see Horner, Sugai, \& Anderson, 2010). For example, acknowledging appropriate student behavior is considered an essential component of SWPBS and frequently includes the distribution of 
tickets to individual students for appropriate behavior that may be traded for tangible items, activities, or other incentives (McKevitt \& Braaksma, 2008). This current system may be conceptualized as an independent group contingency, which is the most frequently used (Litow \& Pumroy, 1975), but may be the least effective, type of group contingency (Gresham \& Gresham, 1982). Randomized dependent group contingencies may be particularly useful in school settings as they require less effort for a teacher or other interventionist to implement because a single student's behavior is recorded rather than all students in a class, which is typical for independent and interdependent group contingencies. More research on group contingencies is necessary and may attempt to incorporate interdependent and dependent group contingencies when independent systems are ineffective or potentially less efficient (i.e., require greater effort for similar outcomes). For example, future research might evaluate the effect of dependent group contingencies on student behavior across grade-level (e.g., a randomly selected class must meet some criterion for the whole grade to receive an incentive) or classrooms (e.g., a randomly selected student must follow the classroom rules throughout one period for the class to receive an incentive) within a SWPBS framework.

Programming common stimuli and maintenance. An important goal of behavioral interventions is to maintain improvements in behavior after the intervention is withdrawn. We found that the primary participants' levels of academic engagement in all groups maintained in the presence of programmed common stimuli. Stokes and Baer (1977) identified that programming common stimuli is an important area for future research due to the potential salience of these stimuli and the ability to incorporate the stimuli in a variety of settings. Few studies have examined the durability of responding in 
the presence of programmed common stimuli without using additional strategies for promoting generalization identified by Stokes and Baer.

Prior research has identified that certain combinations of strategies to promote generalization and response maintenance may be more effective than others (Chandler et al., 1992). In their review, Chandler et al. (1992) found that programming common stimuli was included as a component in $29 \%$ of the most successful studies that promoted generalization of social skills in preschool children. However, most studies that examined maintenance and generalization evaluated a combination of procedures. That is, studies combined programming common stimuli with additional maintenance strategies to successfully maintain improvements in behavior following intervention. For example, Freeland \& Noell $(1999,2002)$ found that a combination of intermittent and delayed reinforcement and programming common stimuli promoted maintenance of responding on math probes across five participants. The package of generalization strategies employed by Freeland and Noell $(1999,2002)$ may be particularly beneficial as the authors sought to program indiscriminable contingencies of reinforcement while incorporating a schedule-correlated stimulus. Nevertheless, it is not possible to identify the unique contributions of a specific maintenance training strategy when procedures are combined in manner described by Freeland and Noell $(1999,2002)$.

The current study extended the literature on maintenance training strategies by evaluating the effects of programming common stimuli on the maintenance of academic intervention. Because programming common stimuli was the only maintenance training strategy evaluated, we were able to determine the utility of this procedure and compare our results to those of prior studies. The current investigation found that programming 
common stimuli led to the maintenance of academic engagement for as long (group 2) or much longer (groups 1 and 3) than prior studies have evaluated maintenance (Freeland \& Noell, 1999, 2002; Hopkins, 1968; Koegel \& Rincover, 1977). Thus, our findings indicate that a combination of maintenance strategies may not be necessary to promote lasting behavior change. Future studies should seek to replicate our findings with additional participants to further evaluate the robust effects of programming common stimuli on maintenance of behavior change.

Our study also extended the literature on group contingencies by evaluating maintenance of behavior change after intervention was withdrawn and a common stimulus remained. Prior research on group contingencies has rarely examined the generality of treatment packages (Maggin, Johnson, Chafouleas, Ruberto, \& Berggren, 2012). Barrish, Saunders, and Wolf (1969) evaluated an interdependent group contingency across math and reading periods. The authors found that reductions in problem behavior were only observed when the contingency was programmed during those periods. Thus, generalization across instructional periods was not observed. No further studies have sought to explicitly program for generalization during group contingency interventions; however, some studies conducted follow-up observations (e.g., Hawkins et al., 2009; Heering \& Wilder, 2006; Rodriguez \& Anderson, 2013) or faded components of the intervention (e.g., Hansen \& Lignugaris-Kraft, 2005; Thorne \& Kamps, 2008).

Fading is a relatively common practice that involves reducing the intensity of an intervention over time (LeBlanc, Hagopian, Maglieri, \& Poling, 2002). For example, Hansen and Lignugaris-Kraft (2005) implemented a randomized dependent group 
contingency to increase the rate of positive statements in nine students with emotional disturbance. After an increase in the number of positive statements was observed, the authors faded the number of days the dependent group contingency was implemented. The authors reported that this fading procedure was unsuccessful as students may have been able to identify when the group contingency would be implemented (i.e., they inadvertently arranged discriminable contingencies). Alternatively, the authors introduced a modified procedure that included a die roll to determine whether the students would receive the reinforcer.

The current study found that programming common stimuli led to maintained levels of academic engagement when the group contingency was withdrawn without requiring additional procedures such as fading the intensity of intervention over time. Thus, fading the intervention may be an unnecessary step in promoting similar levels of appropriate behavior. Eliminating fading requirements entirely may be beneficial because it may decrease the effort or time associated with the treatment without impacting levels of academic engagement during treatment or the durability of academic engagement.

Researchers should also consider programming common stimuli as a strategy to promote maintenance and generalization for other Tier-2 behavioral interventions. Examining different methods to promote generalization and response maintenance may reduce teacher effort associated with the intervention, be more efficient in producing durable behavior change by demonstrating similar gains in less time, or promote greater durability in extinction. For example, Check-In/Check-Out (CICO) is a commonly used intervention in schools in which a student receives feedback for target behavior at scheduled time periods throughout the school day (Filter, McKenna, Benedict, Horner, 
Todd, \& Watson, 2007). Previous research has attempted to fade the intensity of CICO by decreasing the number of times a student receives feedback throughout the day (Campbell \& Anderson, 2011); however, research has not examined the effect of these procedures on the maintenance of behavior change during extinction. Programming common stimuli may be included in these fading procedures to promote more lasting behavior change. For example, participants in CICO carry a point-card to receive feedback from their teachers throughout the day. Using procedures like those described in Freeland and Noell $(1999,2002)$, the color of the point-card may be altered based on the schedule of reinforcement (e.g., white during continuous reinforcement and green during fading) and allow for an examination of responding during extinction. Thus, future research might seek to evaluate the benefits of programming common stimuli during other school-based interventions and identify strategies for improving maintenance if changes in target behavior are not maintained.

Although only group 2 met our termination criteria during the maintenance phase, it is important that future research examine ways to recapture acceptable levels of target behavior after behavior decreases below some predetermined level. Freeland and Noell (1999) found that digits correct on math probes maintained for three participants when programming common stimuli and delayed reinforcement were included in the intervention. Responding eventually decreased to baseline levels during the maintenance phase for two participants. The authors then reintroduced delayed reinforcement, delivered after two worksheets were completed, and found that digits correct returned to equal or higher levels compared to prior treatment phases. The procedures used by Freeland and Noell (1999) may align with Stokes and Baers' (1977) discussion of 
sequential modification. Specifically, when generalization is deficient or not observed, treatment may be implemented under those conditions until generalized responding is observed. Future research might evaluate which components of an intervention are necessary to recapture responding after decreases in the target behavior are observed.

Problem behavior. Low levels of problem behavior were observed across baseline, treatment, and maintenance phases. Although we expected the lowest levels of problem behavior to occur during treatment phases, this effect was only observed for group 3. Minimal levels of problem behavior were observed in group 2, and higher levels of problem behavior occurred during treatment and maintenance phases for group 1.

The current study used academic engagement as our primary dependent variable. Although the reinforcement contingency was based on academic engagement and not problem behavior, we hypothesized that an inverse relationship would exist between levels of academic engagement and levels of problem behavior. Prior research found that compliance increased as problem behavior decreased, even though reinforcement occurred on a fixed-time schedule and was not contingent on the occurrence of either target behavior (e.g., Kodak et al, 2004). Group 3 appeared to engage in zero levels of problem behavior during sessions with high levels of academic engagement, and higher levels of problem behavior coincided with lower levels of academic engagement. Nevertheless, there did not appear to be an inverse relationship between academic engagement and problem behavior for groups 1 and 2. Definitions of the dependent variables and the sampling method may be responsible for the observed inconsistencies in this relationship. 
Certain topographies of problem behavior may have been incompatible with academic engagement. For example, the participant could not engage in negative vocalizations and be academically engaged at the same time, based on definitions of these behaviors. However, other topographies of problem behavior could occur while the participant simultaneously met the criteria for academic engagement (e.g., touching instructional materials that were not part of the task while remaining seated, quiet, and looking at instructional materials). Thus, although the definitions of problem behavior and academic engagement conflicted in some instances, participants could engage in both target behaviors simultaneously.

Our measurement system may have impacted measures of problem behavior and academic engagement. The method of data measurement differed across dependent variables. We used a MTS method to collect data on academic engagement. We measured the frequency of problem behavior. Thus, the participant could have been offtask while engaging in problem behavior during an observation time period and then academically engaged at the moment that the MTS data on academic engagement was recorded. We selected to collect frequency data on problem behavior to ensure that all instances of problem behavior would be noted. Although problem behavior could have occurred within the same interval as academic engagement, the MTS method may prevent an interpretation of the potential inverse relationship between academic engagement and problem behavior. Future studies seeking to examine this relationship might use MTS for both dependent variables and select definitions of behavior that would allow only one dependent variable to be recorded at a time (i.e., academic engagement could not be scored if problem behavior occurred). 
Academic engagement. The current study extends the literature on academic engagement during reading and writing instruction. Prior research has noted the importance of academic engagement as a variable that affects achievement (e.g., Gettinger, 1995; Greenwood, Horton, \& Utley, 2002; Simonsen, Fairbanks, Briesch, Myers, \& Sugai, 2008; Thurlow, Ysseldyke, Graden, \& Algozzine, 1984); however, interventions to increase academic engagement have been implemented with a select number of participants within a larger classroom or group (e.g., Barton-Arwood, Wehby, \& Falk, 2005; Brooks, Todd, Tofflemoyer, \& Horner, 2003; Carnine, 1976; Dunlap et al., 1994). For example, Dunlap et al. examined the effect of assignment choice on two students' academic engagement and disruptive behavior during English and spelling periods. The authors found that providing a choice of assignment was associated with higher levels of academic engagement and lower levels of disruptive behavior relative to baseline for both participants. However, the effects of intervention on other students in the classroom were not measured.

The current study implemented a treatment package that resulted in increased academic engagement for the primary participants and secondary participants. Interventions that improve academic engagement across all students may be particularly beneficial, as prior research has indicated a high level of variability in academic engagement across students, particularly in classes with students performing below benchmark (Wharton-McDonald, Pressley, \& Hampson, 1998).

Reading measures. We observed lower scores on easyCBM measures during the post-intervention assessment. Although this outcome is not ideal, it is important to note that reductions in post-intervention assessment scores are typically observed during the 
summer reading clinic and may relate to differences in the grade level of probes conducted prior to and following the program. The current intervention sought to increase academic engagement during instruction and did not examine instructional variables that may influence acquisition of skills such as pacing and opportunities to respond (Carnine, 1976). Previous research has demonstrated a positive correlation between academic engagement and academic performance (Greenwood et al., 2002) and a negative correlation between problem behavior and academic performance (Malecki \& Elliott, 2002). However, it remains unclear whether a specific amount of academic engagement is necessary to improve performance. More than half of our participants were academically engaged during at least $80 \%$ of intervals during baseline sessions (i.e., DI without additional behavioral intervention). It is unclear whether increasing academic engagement above $80 \%$ will lead to additional improvements in performance.

In addition, the assessment procedures may not adequately represent student performance. That is, a single progress-monitoring probe was used to assess performance pre- and post-intervention. Due to the brevity of curriculum-based measures, other explanations for student performance are plausible (Good et al., 2001). Shinn (2008) identified that curriculum-based measures should include repeated samples of behavior to obtain the most accurate measures of performance. Thus, it would be ideal to conduct multiple assessments across days so that a more representative sample of behavior may be identified. Future studies seeking to evaluate the effect of academic engagement on learning should collect more frequent measures of performance on target assessments. In addition, the same measure could be used during pre- and post-intervention probes to evaluate the impact of academic engagement during instruction on learning. Future 
studies should arrange consistent measures across probes to more accurately measure any gains in performance achieved by higher levels of academic engagement.

Social validity. The results of the TEI-SF showed that the instructors who implemented intervention had ratings of agreed and strongly agreed for seven of the nine items. Instructors indicated that they would be willing to use this procedure to change behavior $(M=4.67$; range, 4 to 5$)$, that this procedure would be appropriate to use without a child's consent ( $M=4.67$; range, 4 to 5$)$, that they had an overall positive reaction to the treatment ( $M=4.67$; range, 4 to 5$)$, and that it would be acceptable to use this treatment with individuals who cannot choose treatment for themselves $(M=4.67$; range, 3 to 5). Ratings indicated that instructors were neutral in their belief that the treatment would result in permanent improvement ( $M=3.00$; range, 2 to 5$)$ and strongly disagreed that the child would experience discomfort during treatment $(M=1.17$; range, 1 to 2). These findings are consistent with prior research on the social validity of group contingencies, which indicated that interventionists reported that group contingencies required little additional time and effort and effectively addressed problem behavior (e.g., Heering \& Wilder, 2006; Rodriguez \& Anderson, 2013).

Instructors' neutral ratings about the lasting effects of the treatment might indicate wariness around the generality of group contingencies. Although the current study demonstrated lasting effects in the form of durable behavior change for at least 20 maintenance sessions across all primary participants, we did not examine the effect of programming common stimuli across settings or teachers. It is unclear how instructors defined the term "permanent improvement" or whether the absence of data collection by 
the instructors or lack of feedback on participant's relatively high levels of academic engagement during the maintenance phase impacted their rating of this item.

\section{Behavioral Mechanisms}

Our findings indicate that the randomized dependent group contingency and programming common physical stimuli led to durable increases in levels of academic engagement in all groups. Certain treatment components included in the current procedures may have impacted the effectiveness of the dependent group contingency on levels of academic engagement. Using a randomized reinforcer is one component of our treatment that has been implemented in previous research on group contingencies to alter motivating operations (MO; i.e., alter the value of a consequence that typically follows behavior and evoke behavior that typically produces that consequence). For example, Heering and Wilder (2006) used a randomized reinforcer similar to our procedures. Preferred activities, determined by mean student preference on a forced-choice assessment, were written on ping-pong balls and selected from a bag after the class period had ended. The findings indicated that providing a randomized reinforcer during a dependent group contingency was effective in increasing on-task behavior during math instruction for rows of students. Theodore et al. (2004) also used a randomized reinforcer; however, potential reinforcers were selected by the teacher and not based on an assessment of students' preferences. Reductions in disruptive behavior were observed across students and type of group contingency. Other studies allowed students to vote for different activities prior to the group contingency (e.g., Williamson et al., 2009). Regardless of the method used in prior studies to select and provide a randomized reinforcer, these strategies improved target behavior. 
Although previous studies arranged different methods for providing reinforcers, the method for selecting reinforcers may be less important than the fact that the identified consequence led to a change in behavior. A consequence can be conceptualized as a reinforcer if the provision of that consequence changes the likelihood of the occurrence of behavior. In studies that used randomized selection of consequences (e.g., Heering \& Wilder, 2006; Theodore et al., 2004), the provision of these consequences improved target behavior.

Preference assessment methodology was developed to assist caregivers, teachers, and practitioners in identifying items that the individual will readily consume that can be provided during behavior-change programs (e.g., DeLeon \& Iwata, 1996; Fisher, Piazza, Bowman, Hagopian, Owens, \& Slevin, 1992; Roane, Vollmer, Ringdahl, \& Marcus, 1998). Although the most frequently used preference assessments allow for the identification of a hierarchy of most-to-less preferred items included in the assessment (e.g., paired-stimulus preference assessment; Fisher et al., 1992), some research shows that even less preferred items will function as reinforcers (Glover, Roane, Kadey, \& Grow, 2008; Penrod, Wallace, \& Dyer, 2008; Roscoe, Iwata, \& Kahng, 2009). For example, Roscoe et al. (1999) found that rates of responding were similar when lowpreference or high-preference items were provided for target behavior. The present study replicated the results of Roscoe et al., because only one stimulus was provided to all group members after a participant met the goal for the dependent group contingency. The group of stimuli from which the instructor randomly selected an item were based on a preference assessment conducted with each participant; yet, the specific item selected during each reinforcement interval may not have been the most preferred item for each 
participant. The inclusion of a preference assessment in the current investigation may have enhanced treatment by ensuring that each participant had highly preferred items included as potential options randomly selected by the instructor. Nevertheless, it may not be necessary to conduct a preference assessment. Future research could evaluate whether including all medium- or low-preference items in the pool of reinforcers from which the instructor randomly selects an item will alter the effectiveness of the randomized reinforcement contingency.

The random selection of a participant to inform access to the reinforcer may have contributed to gains during treatment and response maintenance in the current study. Prior research has identified that the random and anonymous selection of a participant for the dependent group contingency may reduce the potential for negative social consequences for students who do not meet the criterion (see Gresham \& Gresham, 1982; Heering \& Wilder, 2006). However, the behavioral mechanisms responsible for the effects of this treatment component are unknown. It may be the case that randomly selecting a participant on which to base the dependent group contingency created indiscriminable contingencies during intervention. That is, participants were not given information regarding the participant whose behavior would influence the delivery of reinforcement. Indiscriminable contingencies may promote behavior change across all participants instead of changing the behavior of one student for whom the observation will impact reinforcement for the group. Future research should compare randomized dependent group contingencies to typical dependent group contingencies (i.e., the participant who will earn reinforcement for the group is identified prior to treatment) to determine the benefits of randomizing this component of intervention. This research may 
also lead to information that suggests potential behavioral mechanisms responsible for the effects of this variable on behavior.

Including a criterion for reinforcement based on an interval schedule may also have produced indiscriminable contingencies. Prior research has used ratio schedules of reinforcement, such that reinforcement is contingent on the number of times the target behavior is observed (e.g., Gresham \& Gresham, 1982; Hansen \& Lignugaris-Kraft, 2005). For example, Hansen and Lignugaris-Kraft used a dependent group contingency to increase positive statements and decrease negative statements in students enrolled in a self-contained special education classroom. The instructor recorded the frequency of positive statements on the board, and if the randomly selected student emitted four positive statements in a day (i.e., a fixed-ratio 4 schedule of reinforcement), then the whole-class received reinforcement at the end of the day. Recording student behavior in this way is an example of arranging discriminable reinforcement contingencies for the target behavior. Fixed ratio schedules of reinforcement may be more easily discriminable than reinforcement contingencies that are based on fixed or variable intervals.

The specific contingencies arranged in the present study may have included intermittent schedules of reinforcement if participants did not meet the criterion for reinforcement during a session. For example, reinforcement was delivered every $10 \mathrm{~min}$ if the criterion for academic engagement was met by the randomly selected participant during a treatment session. If the criterion was not met, the next session was conducted immediately with no indication to the participants. If the randomly selected participant for the subsequent session met the criterion, then reinforcement occurred after $20 \mathrm{~min}$. Depending on the variability of participant academic engagement, and which participant 
was randomly selected to inform the contingency, the extent to which intermittent reinforcement occurred may have varied across sessions. Variability in intermittent reinforcement schedules may have increased the extent to which reinforcement contingencies were indiscriminable during treatment.

Previous research has shown that indiscriminable contingencies have promoted more durable responding (Freeland \& Noell, 1999, 2002; Guevremont, Osnes, \& Stokes, 1986; Koegel \& Rincover, 1977). In the current study, participants met the criterion for reinforcement in the treatment phase during 90\% of sessions. Participants in group 1 and group 3 met the criterion during all but one session. Participants in group 2 did not meet the criterion during three treatment sessions. Thus, there were occasions on which intermittent reinforcement occurred during treatment, which varied across groups.

Freeland and Noell $(1999,2002)$ combined programming common stimuli and delayed, intermittent reinforcement to promote durable behavior change during a maintenance phase. In the present investigation, intermittent reinforcement occurred infrequently and was not carefully arranged. Nevertheless, the results of the current study and those of Freeland and Noell $(1999,2002)$ were similar. The specific treatment variable(s) (e.g., intermittent reinforcement, programming common stimuli) that produced indiscriminable contingencies and lasting behavior change remain unclear. More research in this area will help isolate the components of treatment that lead to maintenance of behavior.

Another component of intervention that may have influenced academic engagement is the frequency of praise. The instructors provided more praise during treatment than in baseline and maintenance. Previous research has shown increases in 
appropriate student behavior when praise is provided alone (Cossairt, Hall, \& Hopkins, 1973; Sutherland, Wehby, \& Copeland, 2000) or as part of a treatment package (Madsen, Becker, \& Thomas, 1968). For example, Cossairt et al. (1973) found that an increase in the frequency of teacher praise was associated with increased attending behavior in thirdand fourth-grade students. Madsen et al. (1968) found that a treatment package including rules, extinction for inappropriate behavior, and increased levels of teacher praise was more effective for decreasing inappropriate behavior than providing rules only or rules and extinction for inappropriate behavior.

Providing praise during academic tasks may decrease the aversiveness of the task or reduce MOs to escape tasks. If the value of a break from the task decreases, then participants may engage in higher levels of academic engagement instead of problem or off-task behavior. Previous studies found that problem behavior maintained by escape from demands may be successfully treated, and increased levels of compliance may occur, by providing positive reinforcement during academic tasks (e.g., Lalli et al., 1999). Said another way, adding positive reinforcers during tasks created an abolishing operation for escape from the task by decreasing the value of a break and momentarily decreasing the likelihood of behavior that produced a break. The current study manipulated the frequency of praise across treatment phases. Lower levels of praise were provided during baseline and maintenance than during treatment. We observed increases in academic engagement during treatment for all of the primary participants and a proportion of the other participants. However, improvements in academic engagement persisted during the maintenance phase in which the frequency of praise decreased to baseline levels. Therefore, it's unclear whether adding praise during treatment altered the task in some 
way that maintained once praise was reduced, or if some other variable was responsible for changes in behavior.

Programming common stimuli was the final treatment component included in the study that may have promoted greater academic engagement relative to baseline. Pairing the programmed stimulus with reinforcement contingencies may have altered the function of this stimulus. That is, the programmed stimulus may have acquired a discriminative function; it became a discriminative stimulus in the presence of which academic engagement was reinforced. Previous studies evaluating multiple schedules show that repeated pairings of the discriminative stimulus and reinforcement for appropriate behavior are sufficient to establish stimulus control over responding (e.g., Hanley, Iwata, \& Thompson, 2001; Tiger \& Hanley, 2004; Tiger, Hanley, \& Heal, 2006). However, unlike prior studies, the function of the stimulus changed during the maintenance phase. Academic engagement was no longer reinforced in the presence of the programmed stimulus. Previous studies on multiple schedules have not evaluated how manipulations of the function of stimuli following training impact responding. The maintenance of academic responding in the present study suggests that a discriminative stimulus may continue to evoke behavior for an extended time period even if reinforcement contingencies change. These findings have important implications for treatment integrity and maintenance of behavior, and future studies should investigate variables that impact the maintenance of stimulus control.

Prior research on group contingencies have included common stimuli during treatment (Gresham \& Gresham, 1982; Rodriguez \& Anderson, 2013). For example, Rodriguez and Anderson (2013) used a yellow $29.7 \mathrm{~cm}$ x $21 \mathrm{~cm}$ tally chart during 
intervention to record instances of the target behavior. This stimulus was unique to the treatment protocol, and students used a different point card during baseline and throughout the rest of the day (i.e., time periods without treatment). Thus, the tally chart may have been a discriminative stimulus for appropriate behavior. Although prior group contingency research has employed common stimuli, none have evaluated the effect of common stimuli on the maintenance of behavior change. The results of the present study suggest that this would be an important area for further investigation.

\section{Limitations}

Several limitations of the current investigation should be described. First, the alternation of two instructors for each group may be a limitation of the current study. Every instructor conducted sessions in each phase of the study; however, the presence of more than one instructor may have facilitated greater maintenance than a single instructor. Stokes, Baer, and Jackson (1974) identified that training a hand-wave as a social greeting generalized across untrained adults with greater consistency when the response was trained with two adults compared to a single adult. Aspects of their findings, including introducing treatment with the second adult while trends in responding were increasing, do not adequately demonstrate the effect of training the response with multiple adults. The current study is the first to employ multiple instructors implementing a randomized dependent group contingency, the effect of which remains unknown.

The current study implemented a break procedure that differed from prior research on group contingencies. Specifically, breaks were taken at the end of a 10-min session. Thus, multiple breaks may have occurred during the $2-\mathrm{hr}$ instructional period. Prior research on group contingencies implemented one session for an entire class period 
with a break provided at the end. The amount of time needed to implement interventions is a critical factor that may impact instructors' selection of an intervention (Elliott, 1988; Han \& Weiss, 2005). Similarly, time away from instruction may impact instructors' selection of a strategy or their fidelity of implementation. It is unclear whether our procedure may have led to more time away from instruction compared to previous research. However, it is likely that time away from instruction in the current study is consistent with prior research. For example, Rodriguez and Anderson (2013) provided 15 min of free access at the end of class if the goal was met. The greatest amount of time spent implementing reinforcement procedures in the current study was $7 \mathrm{~min}$ in the $2-\mathrm{hr}$ instructional period. Future research might evaluate teacher's selection, rating of acceptability, and the effectiveness of intervention procedures that require reinforcement to be delivered multiple times during a class period compared to reinforcement delivered at the end of the period or day.

The intervention package in the current study included a number of treatment components that may have led to improvements in behavior. A component analysis may provide greater understanding of the specific variables of the current intervention that may have influenced the observed behavior change and maintenance after treatment was withdrawn.

Finally, the procedures in the current study may not be feasible for small-group instruction in a typical classroom setting. We sought to evaluate the effect of programming common stimuli and randomized dependent group contingencies on academic engagement and the maintenance of behavior change. Thus, we incorporated study procedures that aligned with our research questions. Certain aspects of the 
intervention may be less feasible than others in natural settings. For example, we used a 30-s MTS procedure to measure academic engagement, although other studies have used much longer intervals. For example, Williamson et al. (2009) used a 5-min MTS procedure. Although lengthier MTS intervals may be more feasible to conduct in natural settings, previous research has indicated that MTS may most accurately represent the true occurrence of behavior for intervals up to 120 s (e.g., Powell et al., 1975; Powell et al., 1977) with decreased accuracy for longer intervals. Future research should consider sampling procedures that measure behavior in a way that is both accurate and feasible for teachers to use during instruction.

The current study contributed to the limited research on randomized dependent group contingencies and methods to promote the generality of these treatment packages. The results of the current study showed that the randomized dependent group contingency produced improvements in academic engagement. Furthermore, including a programmed common stimulus across phases of the study produced maintenance of treatment gains for two of the three groups. Programming common stimuli is one strategy that may promote responding in extinction, and future research should examine other methods to promote the generalization and maintenance of treatment packages. 


\section{APPENDIX A}

\section{SAMPLE DATA SHEET}

Contingency based on Student \#

\begin{tabular}{|l|ll|ll|lll|l|}
\hline \multicolumn{7}{|c|}{ Student \# } \\
\hline Interval & \multicolumn{2}{|c|}{1} & \multicolumn{2}{|c|}{2} & \multicolumn{2}{|c|}{3} & \multicolumn{2}{|c|}{4} \\
\hline 0:00-0:30 & + & - & + & - & + & - & + & - \\
\hline $0: 30-1: 00$ & + & - & + & - & + & - & + & - \\
\hline $1: 00-1: 30$ & + & - & + & - & + & - & + & - \\
\hline $1: 30-2: 00$ & + & - & + & - & + & - & + & - \\
\hline $2: 00-2: 30$ & + & - & + & - & + & - & + & - \\
\hline $2: 30-3: 00$ & + & - & + & - & + & - & + & - \\
\hline $3: 00-3: 30$ & + & - & + & - & + & - & + & - \\
\hline $3: 30-4: 00$ & + & - & + & - & + & - & + & - \\
\hline $4: 00-4: 30$ & + & - & + & - & + & - & + & - \\
\hline $4: 30-5: 00$ & + & - & + & - & + & - & + & - \\
\hline $5: 00-5: 30$ & + & - & + & - & + & - & + & - \\
\hline $5: 30-6: 00$ & + & - & + & - & + & - & + & - \\
\hline $6: 00-6: 30$ & + & - & + & - & + & - & + & - \\
\hline $6: 30-7: 00$ & + & - & + & - & + & - & + & - \\
\hline $7: 00-7: 30$ & + & - & + & - & + & - & + & - \\
\hline $7: 30-8: 00$ & + & - & + & - & + & - & + & - \\
\hline $8: 00-8: 30$ & + & - & + & - & + & - & + & - \\
\hline $8: 30-9: 00$ & + & - & + & - & + & - & + & - \\
\hline $9: 00-9: 30$ & + & - & + & - & + & - & + & - \\
\hline $9: 30-10: 00$ & + & - & + & - & + & - & + & - \\
\hline & & & & & & & & \\
\hline Total w/ AE & & & & & & & & \\
\hline
\end{tabular}

\begin{tabular}{|l|}
\hline Notes \\
$\mid$ |
\end{tabular}

\begin{tabular}{|c|l|l|l|l|}
\hline Student & 1 & 2 & 3 & 4 \\
\hline $\begin{array}{c}\text { \# of } \\
\text { Problem } \\
\text { Behaviors }\end{array}$ & & & & \\
\hline \multicolumn{5}{|l|}{} \\
\hline $\begin{array}{l}\text { \# of Praise } \\
\text { Statements }\end{array}$ & & & & \\
\hline
\end{tabular}




\section{APPENDIX B}

\section{FIDELITY OF IMPLEMENTATION CHECKLIST}

Fidelity of Implementation Checklist

Date Data Collector

Instructor

\begin{tabular}{|c|c|c|c|c|c|c|}
\hline Daily Components & 1 & 2 & 3 & 4 & 5 & 6 \\
\hline $\begin{array}{l}\text { Instructor delivered script at beginning } \\
\text { of day }\end{array}$ & $\begin{array}{c}+ \\
- \\
\mathrm{N} / \mathrm{O}\end{array}$ & $\begin{array}{c}+ \\
- \\
\mathrm{N} / \mathrm{O}\end{array}$ & $\begin{array}{c}+ \\
- \\
\mathrm{N} / \mathrm{O}\end{array}$ & $\begin{array}{c}+ \\
- \\
\mathrm{N} / \mathrm{O}\end{array}$ & $\begin{array}{c}+ \\
- \\
\mathrm{N} / \mathrm{O}\end{array}$ & $\begin{array}{c}+ \\
- \\
\mathrm{N} / \mathrm{O}\end{array}$ \\
\hline $\begin{array}{l}\text { TX: Instructor presents yellow paper } \\
\text { with goal and says, "This is your goal } \\
\text { for today." }\end{array}$ & $\begin{array}{c}+ \\
- \\
\mathrm{N} / \mathrm{O}\end{array}$ & $\begin{array}{c}+ \\
- \\
\mathrm{N} / \mathrm{O}\end{array}$ & $\begin{array}{c}+ \\
- \\
\mathrm{N} / \mathrm{O}\end{array}$ & $\begin{array}{c}+ \\
- \\
\mathrm{N} / \mathrm{O}\end{array}$ & $\begin{array}{c}+ \\
- \\
\mathrm{N} / \mathrm{O}\end{array}$ & $\begin{array}{c}+ \\
- \\
\mathrm{N} / \mathrm{O}\end{array}$ \\
\hline $\begin{array}{l}\text { BL: Instructor does not present yellow } \\
\text { paper with goal and says, "There's no } \\
\text { goal for today, so we won't be able to } \\
\text { earn any rewards or breaks." }\end{array}$ & $\begin{array}{c}+ \\
- \\
\mathrm{N} / \mathrm{O}\end{array}$ & $\begin{array}{c}+ \\
- \\
\mathrm{N} / \mathrm{O}\end{array}$ & $\begin{array}{c}+ \\
- \\
\mathrm{N} / \mathrm{O}\end{array}$ & $\begin{array}{c}+ \\
- \\
\mathrm{N} / \mathrm{O}\end{array}$ & $\begin{array}{c}+ \\
- \\
\mathrm{N} / \mathrm{O}\end{array}$ & $\begin{array}{c}+ \\
- \\
\mathrm{N} / \mathrm{O}\end{array}$ \\
\hline $\begin{array}{l}\text { Instructor delivers appropriate number } \\
\text { of praise statements during each session } \\
(\mathrm{BL}:<5 ; \mathrm{TX}:>15)\end{array}$ & $\begin{array}{c}+ \\
- \\
\mathrm{N} / \mathrm{O}\end{array}$ & $\begin{array}{c}+ \\
- \\
\mathrm{N} / \mathrm{O}\end{array}$ & $\begin{array}{c}+ \\
- \\
\mathrm{N} / \mathrm{O}\end{array}$ & $\begin{array}{c}+ \\
- \\
\mathrm{N} / \mathrm{O}\end{array}$ & $\begin{array}{c}+ \\
- \\
\mathrm{N} / \mathrm{O}\end{array}$ & $\begin{array}{c}+ \\
- \\
\mathrm{N} / \mathrm{O}\end{array}$ \\
\hline \multicolumn{7}{|l|}{ Goal Met } \\
\hline $\begin{array}{l}\text { Instructor delivers script (i.e., "[student } \\
\text { name] followed the rules! Now let's see } \\
\text { what you will get to have during your } \\
\text { break.") }\end{array}$ & $\begin{array}{c}+ \\
- \\
\mathrm{N} / \mathrm{O}\end{array}$ & $\begin{array}{c}+ \\
- \\
\mathrm{N} / \mathrm{O}\end{array}$ & $\begin{array}{c}+ \\
- \\
\mathrm{N} / \mathrm{O}\end{array}$ & $\begin{array}{c}+ \\
- \\
\mathrm{N} / \mathrm{O}\end{array}$ & $\begin{array}{c}+ \\
- \\
\mathrm{N} / \mathrm{O}\end{array}$ & $\begin{array}{c}+ \\
- \\
\mathrm{N} / \mathrm{O}\end{array}$ \\
\hline Delivers access to reinforcer for $1 \mathrm{~min}$ & $\begin{array}{c}+ \\
- \\
\mathrm{N} / \mathrm{O}\end{array}$ & $\begin{array}{c}+ \\
- \\
\mathrm{N} / \mathrm{O}\end{array}$ & $\begin{array}{c}+ \\
- \\
\mathrm{N} / \mathrm{O}\end{array}$ & $\begin{array}{c}+ \\
- \\
\mathrm{N} / \mathrm{O}\end{array}$ & $\begin{array}{c}+ \\
- \\
\mathrm{N} / \mathrm{O}\end{array}$ & $\begin{array}{c}+ \\
- \\
\mathrm{N} / \mathrm{O}\end{array}$ \\
\hline $\begin{array}{l}\text { Instructor does not deliver reinforcement } \\
\text { when the goal is met during the } \\
\text { maintenance phase. }\end{array}$ & $\begin{array}{c}+ \\
- \\
\mathrm{N} / \mathrm{O}\end{array}$ & $\begin{array}{c}+ \\
- \\
\mathrm{N} / \mathrm{O}\end{array}$ & $\begin{array}{c}+ \\
- \\
\mathrm{N} / \mathrm{O}\end{array}$ & $\begin{array}{c}+ \\
- \\
\mathrm{N} / \mathrm{O}\end{array}$ & $\begin{array}{c}+ \\
- \\
\mathrm{N} / \mathrm{O}\end{array}$ & $\begin{array}{c}+ \\
- \\
\mathrm{N} / \mathrm{O}\end{array}$ \\
\hline \multicolumn{7}{|l|}{ Goal NOT Met } \\
\hline $\begin{array}{l}\text { Instructor continues to deliver } \\
\text { instruction }\end{array}$ & $\begin{array}{c}+ \\
- \\
\mathrm{N} / \mathrm{O}\end{array}$ & $\begin{array}{c}+ \\
- \\
\mathrm{N} / \mathrm{O}\end{array}$ & $\begin{array}{c}+ \\
- \\
\mathrm{N} / \mathrm{O}\end{array}$ & $\begin{array}{c}+ \\
- \\
\mathrm{N} / \mathrm{O}\end{array}$ & $\begin{array}{c}+ \\
- \\
\mathrm{N} / \mathrm{O}\end{array}$ & $\begin{array}{c}+ \\
- \\
\mathrm{N} / \mathrm{O}\end{array}$ \\
\hline \multicolumn{7}{|l|}{ Problem Behavior } \\
\hline Instructor ignores problem behavior & $\begin{array}{c}+ \\
- \\
\mathrm{N} / \mathrm{O}\end{array}$ & $\begin{array}{c}+ \\
- \\
\mathrm{N} / \mathrm{O}\end{array}$ & $\begin{array}{c}+ \\
- \\
\mathrm{N} / \mathrm{O}\end{array}$ & $\begin{array}{c}+ \\
- \\
\mathrm{N} / \mathrm{O}\end{array}$ & $\begin{array}{c}+ \\
- \\
\mathrm{N} / \mathrm{O}\end{array}$ & $\begin{array}{c}+ \\
- \\
\mathrm{N} / \mathrm{O}\end{array}$ \\
\hline $\begin{array}{l}\text { Instructor praises only appropriate } \\
\text { student behavior }\end{array}$ & $\begin{array}{c}+ \\
- \\
\mathrm{N} / \mathrm{O}\end{array}$ & $\begin{array}{c}+ \\
- \\
\mathrm{N} / \mathrm{O}\end{array}$ & $\begin{array}{c}+ \\
- \\
\mathrm{N} / \mathrm{O}\end{array}$ & $\begin{array}{c}+ \\
- \\
\mathrm{N} / \mathrm{O}\end{array}$ & $\begin{array}{c}+ \\
- \\
\mathrm{N} / \mathrm{O}\end{array}$ & $\begin{array}{c}+ \\
- \\
\mathrm{N} / \mathrm{O}\end{array}$ \\
\hline
\end{tabular}




APPENDIX C
MSWO PREFERENCE ASSESSMENT DATA SHEET
Group \#_ Participant \#_ Observer_ Date_ _
\begin{tabular}{|l|l|l|l|l|l|l|}
\hline Item & $\mathbf{1}$ & $\mathbf{2}$ & $\mathbf{3}$ & $\mathbf{4}$ & $\mathbf{5}$ & $\mathbf{6}$ \\
\hline Hot Wheels & & & & & & \\
\hline Transformers & & & & & & \\
\hline Mixers & & & & & & \\
\hline Erasers & & & & & & \\
\hline Superheroes & & & & & & \\
\hline Pet Shops & & & & & & \\
\hline Pink Legos & & & & & & \\
\hline
\end{tabular}

\begin{tabular}{|l|l|l|l|l|l|l|}
\hline \multicolumn{1}{|c|}{ Item } & $\mathbf{1}$ & $\mathbf{2}$ & $\mathbf{3}$ & $\mathbf{4}$ & $\mathbf{5}$ & $\mathbf{6}$ \\
\hline Hot Wheels & & & & & & \\
\hline Transformers & & & & & & \\
\hline Mixers & & & & & & \\
\hline Erasers & & & & & & \\
\hline Superheroes & & & & & & \\
\hline Pet Shops & & & & & & \\
\hline Pink Legos & & & & & & \\
\hline
\end{tabular}

\begin{tabular}{|l|l|l|l|l|l|l|}
\hline \multicolumn{1}{|c|}{ Item } & $\mathbf{1}$ & $\mathbf{2}$ & $\mathbf{3}$ & $\mathbf{4}$ & $\mathbf{5}$ & $\mathbf{6}$ \\
\hline Hot Wheels & & & & & & \\
\hline Transformers & & & & & & \\
\hline Mixers & & & & & & \\
\hline Erasers & & & & & & \\
\hline Superheroes & & & & & & \\
\hline Pet Shops & & & & & & \\
\hline Pink Legos & & & & & & \\
\hline
\end{tabular}




\section{APPENDIX D}

CALCULATING CONDITIONAL PROBABILITIES

Peer attention

\begin{tabular}{|c|c|c|c|}
\hline Behavior & $\mathrm{B}$ & $\mathrm{B}+\mathrm{C}$ & $\mathrm{B}+\mathrm{C} / \mathrm{B}$ \\
\hline Present & & & \\
\hline Absent & & & \\
\hline
\end{tabular}

Teacher attention

\begin{tabular}{|c|c|c|c|}
\hline Behavior & B & B $+\mathrm{C}$ & $\mathrm{B}+\mathrm{C} / \mathrm{B}$ \\
\hline Present & & & \\
\hline Absent & & & \\
\hline
\end{tabular}

Escape

\begin{tabular}{|c|c|c|c|}
\hline Behavior & $\mathrm{B}$ & $\mathrm{B}+\mathrm{C}$ & $\mathrm{B}+\mathrm{C} / \mathrm{B}$ \\
\hline Present & & & \\
\hline Absent & & & \\
\hline
\end{tabular}

Other behavior

\begin{tabular}{|c|c|c|c|}
\hline Behavior & B & $\mathrm{B}+\mathrm{C}$ & $\mathrm{B}+\mathrm{C} / \mathrm{B}$ \\
\hline Present & & & \\
\hline Absent & & & \\
\hline
\end{tabular}




\section{APPENDIX E}

\section{TREATMENT EVALUATION INVENTORY SHORT-FORM}

\section{Treatment Evaluation Inventory Short-Form (TEI-SF)}

Please complete the items listed below by placing a checkmark on the line next to each question that best indicates how you feel about the treatment. Please read the items carefully because a checkmark accidentally placed on one space rather than another may not represent the meaning you intended.

\begin{tabular}{|c|c|c|c|c|c|}
\hline & $\begin{array}{l}\text { Strongly } \\
\text { Disagree }\end{array}$ & Disagree & Neutral & Agree & $\begin{array}{c}\text { Strongly } \\
\text { Agree }\end{array}$ \\
\hline $\begin{array}{l}\text { 1. I find this } \\
\text { treatment to be } \\
\text { an acceptable } \\
\text { way of dealing } \\
\text { with the child's } \\
\text { behavior. }\end{array}$ & & & & & \\
\hline $\begin{array}{l}\text { 2. I would be } \\
\text { willing to use } \\
\text { this procedure } \\
\text { if I had to } \\
\text { change the } \\
\text { child's } \\
\text { behavior. }\end{array}$ & & & & & \\
\hline $\begin{array}{l}\text { 3. I believe } \\
\text { that it would } \\
\text { be acceptable } \\
\text { to use this } \\
\text { treatment } \\
\text { without } \\
\text { children's } \\
\text { consent. }\end{array}$ & & & & & \\
\hline $\begin{array}{l}\text { 4. I like the } \\
\text { procedures } \\
\text { used in this } \\
\text { treatment. }\end{array}$ & & & & & \\
\hline $\begin{array}{l}5 . \text { I believe } \\
\text { this treatment } \\
\text { is likely to be } \\
\text { effective. }\end{array}$ & & & & & \\
\hline
\end{tabular}




\begin{tabular}{|c|c|c|c|c|c|}
\hline & $\begin{array}{l}\text { Strongly } \\
\text { Disagree }\end{array}$ & Disagree & Neutral & Agree & $\begin{array}{l}\text { Strongly } \\
\text { Agree }\end{array}$ \\
\hline $\begin{array}{l}6 . \text { I believe the } \\
\text { child will } \\
\text { experience } \\
\text { discomfort } \\
\text { during the } \\
\text { treatment. }\end{array}$ & & & & & \\
\hline $\begin{array}{l}\text { 7. I believe this } \\
\text { treatment is } \\
\text { likely to result } \\
\text { in permanent } \\
\text { improvement. }\end{array}$ & & & & & \\
\hline $\begin{array}{l}8 . \text { I believe it } \\
\text { would be } \\
\text { acceptable to } \\
\text { use this } \\
\text { treatment with } \\
\text { individuals } \\
\text { who cannot } \\
\text { choose } \\
\text { treatments } \\
\text { themselves. }\end{array}$ & & & & & \\
\hline $\begin{array}{l}\text { 9. Overall, I } \\
\text { have a positive } \\
\text { reaction to this } \\
\text { treatment. }\end{array}$ & & & & & \\
\hline
\end{tabular}




\section{REFERENCES CITED}

Athens, E. S., Vollmer, T. R., \& St. Peter Pipkin, C. C. (2007). Shaping academic task engagement with percentile schedules. Journal of Applied Behavior Analysis, 40, 475-488.

Alonzo, J. \& Tindal, G. (2009). Alternate form and test-retest reliability of easyCBM reading measures (Report No. 0906). Eugene, OR: Behavioral Research and Teaching.

Alonzo, J. \& Tindal, G. (2012). Teachers' manual for regular easyCBM: Getting the most out of the system. Eugene, OR: Behavioral Research and Teaching.

Alonzo, J., Park, B. J., \& Tindal, G. (2013). Examining the internal structure of the easyCBM reading measures, grades K-5 (Report No. 1302). Eugene, OR: Behavioral Research and Teaching.

Baer, R. A., Blount, R. L., Detrich, R., \& Stokes, T. F. (1987). Using intermittent reinforcement to program maintenance of verbal/nonverbal correspondence. Journal of Applied Behavior Analysis, 20, 179-184.

Baer, D. M., Wolf, M. M., \& Risley, T. R. (1987). Some still-current dimensions of applied behavior analysis. Journal of Applied Behavior Analysis, 20, 313-327.

Barton-Arwood, S.M., Wehby, J.M., \& Falk, K.B. (2005). Reading instruction for elementary-age students with emotional and behavioral disorders: Academic and behavioral outcomes. Exceptional Children, 72, 7-27.

Brooks, A., Todd., A. W., Tofflemeyer, S., \& Horner, R. H. (2003). Use of functional assessment and a self-management system to increase academic engagement and work completion. Journal of Positive Behavior Interventions, 5, 144-152.

Call, N. A., Pabico, R. S., Findley, A. J., \& Valentino, A. L. (2011). Differential reinforcement with and without blocking as treatment for elopement. Journal of Applied Behavior Analysis, 44, 903-907.

Carnine, D. W. (1976). Effects of teacher-presentation rates on off-task behavior, answering correctly, and participation. Journal of Applied Behavior Analysis, 9, 199-206.

Campbell, A. \& Anderson, C. M. (2011). Check-in/check-out: A systematic evaluation and component analysis. Journal of Applied Behavior Analysis, $44,315-326$. 
Cobb, J. A. (1972). Relationship of discrete classroom behaviors to fourth-grade academic achievement. Journal of Educational Psychology, 63, 74-80.

Cossairt, A., Hall, R. V., \& Hopkins, B. L. (1973). The effects of experimenter's instructions, feedback, and praise on teacher praise and student attending behavior. Journal of Applied Behavior Analysis, 6, 89-100.

Coyne, M. D., Kame'enui, E. J., \& Simmons, D. C. (2004). Improving beginning reading instruction and intervention for students with LD: Reconciling "all" with "each". Journal of Learning Disabilities, 37, 231-239.

Davis, P. K. \& Blankenship, C. J. (1996). Group-oriented contingencies: Applications for community rehabilitation programs. Vocational Evaluation and Work Adjustment Bulletin, 29, 114-118.

DeLeon, I. G., \& Iwata, B. A. (1996). Evaluation of a multiple-stimulus presentation format for assessing reinforcer preference. Journal of Applied Behavior Analysis, 29, 519-532.

Elliott, S. N. (1988). Acceptability of behavioral treatments: Review of variables influence treatment selection. Professional Psychology: Research and Practice, 19, 68-80.

Embry, D. D. (2002). The good behavior game: A best practice candidate as a universal behavioral vaccine. Clinical Child and Family Psychology Review, 5, 273-297.

Filter, K. J., McKenna, M. K., Benedict, E. A., Horner, R. H., Todd, A. W., \& Watson, J. (2007). Check in/check out: A post-hoc evaluation of an efficient, secondary-level targeted intervention for reducing problem behavior in schools. Education and Treatment of Children, 30, 69-84.

Finn, C. A. \& Sladeczek, I. E. (2001). Assessing the social validity of behavioral interventions: A review of treatment acceptability measures. School Psychology Quarterly, 16, 176-206.

Fisher, W., Piazza, C. C., Bowman, L. G., Hagopian, L. P., Owens, J. C., \& Slevin, I. (1992). A comparison of two approaches for identifying reinforcers for persons with severe and profound disabilities. Journal of Applied Behavior Analysis, 25, 491-498.

Freeland, J. T. \& Noell, G. H. (1999). Maintaining accurate math responses in elementary school students: The effects of delayed intermittent reinforcement and programming common stimuli. Journal of Applied Behavior Analysis, 32, 211-215. 
Freeland, J. T. \& Noell, G. H. (2002). Programming for maintenance: An investigation of delayed intermittent reinforcement and common stimuli to create indiscriminable contingencies. Journal of Behavioral Education, 11, $5-18$.

Gettinger, M. (1995). Increasing academic learning time. In A. Thomas, \& J. Grimes, (Eds.), Best practices in school psychology, vol. III (pp. 943955). Washington, DC: National Association of School Psychologists.

Glover, A. C., Roane, H. S., Kadey, H. J., \& Grow, L. L. (2008). Preference for reinforcers under progressive- and fixed-ratio schedules: A comparison of single and concurrent arrangements. Journal of Applied Behavior Analysis, 41, 163-176.

Goldsmith, T. R., LeBlanc, L. A., Sautter, R. A. (2007). Teaching intraverbal behavior to children with autism. Research in Autism Spectrum Disorders, $1,1-13$.

Good, R. H., Kaminski, R. A., Simmons, D., \& Kame'enui, E. J., (2001). Using dynamic indicators of basic early literacy sills (DIBELS) in an outcomesdriven model: Steps to reading success. Oregon School Study Council, 44, $2-27$.

Greenwood, C. R., Horton, B. T., \& Utley, C. A. (2002). Academic engagement: Current perspectives on research and practice. School Psychology Review, 31, 328-349.

Gresham, F. M. \& Gresham, G. N. (1982). Interdependent, dependent, and independent group contingencies for controlling disruptive behavior. The Journal of Special Education, 16, 101-110.

Guevremont, D. C., Osnes, P. G., \& Stokes, T. F. (1986). Programming maintenance after correspondence training interventions with children. Journal of Applied Behavior Analysis, 19, 215-219.

Hallahan, D. P., Lloyd, J., Kosiewicz, M. M., Kauffman, J. T., \& Graves, A. W. (1979). Self-monitoring of attention as a treatment for a learning disabled boy's off-task behavior. Learning Disability Quarterly, 2, 24-32.

Han, S. S. \& Weiss, B. (2005). Sustainability of teacher implementation of school-based mental health programs. Journal of Abnormal Child Psychology, 33, 665-679.

Hanley, G. P., Iwata, B. A., \& Thompson, R. H. (2001). Reinforcement schedule thinning following treatment with functional communication training. Journal of Applied Behavior Analysis, 34, 17-38. 
Hansen, S. D. \& Lignugaris-Kraft, B. (2005). Effects of a dependent group contingency on the verbal interactions of middle school students with emotional disturbance. Behavioral Disorders, 30, 170-184.

Hawkins, R. O., Musti-Rao, S., Hughes, C., Berry, L., McGuire, S. (2009). Applying a randomized interdependent group contingency component to classwide peer tutoring for multiplication fact fluency. Journal of Behavioral Education, 18, 300-318.

Heering, P. W. \& Wilder, D. A. (2006). The use of dependent group contingencies to increase on-task behavior in two general education classrooms. Education and Treatment of Children, 29, 459-468.

Herman, S. H. \& Tramontana, J. (1971). Instructions and group versus individual reinforcement in modifying disruptive group behavior. Journal of Applied Behavior Analysis, 4, 113-119.

Hopkins, B. L. (1968). Effects of candy and social reinforcement, instructions, and reinforcement schedule leaning on the modification and maintenance of smiling. Journal of Applied Behavior Analysis, 1, 121-129.

Horner, R. H., Carr, E. G., Halle, J., McGee, G., Odom, S., \& Worley, M. (2005). The use of single subject research to identify evidence-based practice in special education. Exceptional Children, 2, 165-179.

Horner, R. H., Sugai, G., \& Anderson, C. M. (2010). Examining the evidence base for school-wide positive behavior support. Focus on Exceptional Children, 42, 1-15.

Iwata, B. A., Pace, G. M., Cowdery, G. E., \& Miltenberger, R. G. (1994). What makes extinction work: An analysis of procedural form and function. Journal of Applied Behavior Analysis, 27, 131-144.

Johnson, B. M., Miltenberger, R. G., Egemo-Helm, K., Jostad, C. M., Flessner, C., \& Gatheridge, B. (2005). Evaluation of behavioral skills training for teaching abduction-prevention skills to young children. Journal of Applied Behavior Analysis, 38, 67-78.

Kazdin, A. E. \& Polster, R. (1973). Intermittent token reinforcement and response maintenance in extinction. Behavior Therapy, 4, 386-391.

Kelley, M. L., Heffer, R. W., Gresham, F. M., Elliott, S. N. (1989). Development of a modified treatment evaluation inventory. Journal of Psychopathology \& Behavioral Assessment, 11, 235-247. 
Kodak, T., Miltenberger, R. G., \& Romaniuk, C. (2003). The effects of differential negative reinforcement of other behavior and noncontingent escape on compliance. Journal of Applied Behavior Analysis, 36, 379-382.

Koegel, R. L. \& Rincover, A. (1977). Research on the difference between generalization and maintenance in extra-therapy responding. Journal of Applied Behavior Analysis, 10, 1-12.

Lalli, J. S., Vollmer, T. R., Progar, P. R., Wright, C., Borrero, J., Daniel, D., Hoffner Barthold, C., Tocco, K., \& May, W. (1999). Competition between positive and negative reinforcement in the treatment of escape behavior. Journal of Applied Behavior Analysis, 32, 285-296.

Lane, K. L., Smither, R., Huseman, R., Guffey, J., \& Fox, J. (2007). A functionbased intervention to decrease disruptive behavior and increase academic engagement. Journal of Early Intensive Behavior Interventions, 3-4, 348364.

Layer, S. A., Hanley, G. P., Heal, N. A., \& Tiger, J. H. (2008). Determining individual preschoolers' preferences in a group arrangement. Journal of Applied Behavior Analysis, 41, 25-37.

Leflot, G., van Lier, P. A. C., Onghena, P., \& Colpin, H. (2013). The role of children's on-task behavior in the prevention of aggressive behavior development and peer rejection: A randomized controlled study of the good behavior game in Belgian elementary classrooms. Journal of School Psychology, 51, 187-199.

Litow, L. \& Pumroy, D. K. (1975). A brief review of classroom group-oriented contingencies. Journal of Applied Behavior Analysis, 8, 341-347.

Lomas, J. E., Fisher, W. W., \& Kelley, M. E. (2010). Effects of variable-time delivery of food items and praise on problem behavior reinforced by escape. Journal of Applied Behavior Analysis, 43, 425-435.

Madsen, C. H., Jr., Becker, W. C., Thomas, D. R. (1968). Rules, praise, and ignoring: Elements of elementary classroom control. Journal of Applied Behavior Analysis, 1, 139-150.

Maggin, D. M., Johnson, A. H., Chafouleas, S. M., Ruberto, L. M., \& Berggren, M. (2012). A systematic evidence review of school-based group contingency interventions for students with challenging behavior. Journal of School Psychology, 50, 625-654. 
Malecki, C. K. \& Elliott, S. N. (2002). Children's social behaviors as predictors of academic achievement: A longitudinal analysis. School Psychology Quarterly, 17, 1-23.

Martens, B. K., DiGennaro, F. D., Reed, D. D., Szczech, F. M., \& Rosenthal, B. D. (2008). Contingency space analysis: An alternative method for identifying contingent relations from observational data. Journal of Applied Behavior Analysis, 41, 69-81.

McKevitt, B. C., \& Braaksma, A. D. (2008). Best practices in developing a positive behavior support system at the school level. In A. Thomas \& J. Grimes (Eds.), (5th ed.). Best practices in school psychology, Vol. 2 (pp. 735-748). Washington, DC: National Association of School Psychologists.

Mesmer, E. M., Duhon, G. J., \& Dodson, K. G. (2007). The effects of programming common stimuli for enhancing stimulus generalization of academic behavior. Journal of Applied Behavior Analysis, 40, 553-557.

Miltenberger, R. G., Flessner, C., Gatheridge, B., Johnson, B., Satterlund, M., \& Egemo, K. (2004). Evaluation of behavioral skills training to prevent gun play in children. Journal of Applied Behavior Analysis, 37, 513-516.

National Reading Panel. (2000). Teaching children to read: An evidence-based assessment of the scientific research literature on reading and its implications for reading instruction: Reports of the subgroups. Bethesda, MD: National Institute of Child Health and Human Development.

Patterson, G. R. (1965). An application of conditioning techniques to the control of a hyperactive child. In L. P. Ullman and L. Krasner (Eds.), Case studies in behavior modification. New York: Holt, Rinehart, and Winston.

Penrod, B., Wallace, M. D., \& Dyer, E. J. (2008). Assessing potency of high- and low-preference reinforcers with respect to response rate and response patterns. Journal of Applied Behavior Analysis, 41, 177-188.

Popkin, J. \& Skinner, C. H. (2003). Enhancing academic performance in a classroom serving students with serious emotional disturbance: Interdependent group contingencies with randomly selected components. School Psychology Review, 32, 282-295.

Powell, J., Martindale, A., \& Kulp, S. (1975). An evaluation of time-sample measures of behavior. Journal of Applied Behavior Analysis, 8, 463-469. 
Powell, J., Martindale, B., Kulp, S., Martindale, A., \& Bauman, R. (1977). Taking a closer look: Time sampling and measurement error. Journal of Applied Behavior Analysis, 10, 325-332.

Repp, A. C., Deitz, D. E., Boles, S. M., Deitz, S. M., \& Repp, C. F. (1976). Differences among common methods for calculating interobserver agreement. Journal of Applied Behavior Analysis, 9, 109-113.

Roane, H. S., Falcomata, T. S., \& Fisher, W. W. (2007). Applying the behavioral economics principle of unit price to DRO schedule thinning. Journal of Applied Behavior Analysis, 40, 529-534.

Roane, H. S., Vollmer, T. R., Ringdahl, J. E., \& Marcus, B. A. (1998). Evaluation of a brief stimulus preference assessment. Journal of Applied Behavior Analysis, 31, 605-620.

Rodriguez, B. J. \& Anderson, C. M. (2013). Integrating a social behavior intervention during small group academic instruction using a total group criterion intervention. Journal of Positive Behavior Interventions, 1-12.

Rolider, N. U., Iwata, B. A., \& Bullock, C. E. (2012). Influences of response rate and distribution on the calculation of interobserver reliability scores. Journal of Applied Behavior Analysis, 45, 753-762.

Romaniuk, C., Miltenberger, R., Conyers, C., Jenner, N., Jurgens, M., \& Ringenberg, C. (2002). The influence of activity choice on problem behaviors maintained by escape versus attention. Journal of Applied Behavior Analysis, 35, 349-362.

Roscoe, E. M., Iwata, B. A., \& Kahng, S. (1999). Relative versus absolute reinforcement effects: Implications for preference assessments. Journal of Applied Behavior Analysis, 32, 479-493.

Sadler, C. \& Sugai, G. (2009). Effective behavior and instructional support: A district model for early identification and prevention of reading and behavior problems. Journal of Positive Behavior Interventions, 11, 35-46.

Sarokoff, R. A. \& Sturmey, P. (2004). The effects of behavioral skills training on staff implementation of discrete-trial teaching. Journal of Applied Behavior Analysis, 37, 535-538.

Schwarz, M. K. \& Hawkins, R. P. (1970) Application of delayed reinforcement procedures to the behavior of an elementary school child. Journal of Applied Behavior Analysis, 3, 85-96. 
Shinn, M. (2008). Best practices for using curriculum based measurement in a problem-solving model. In A. Thomas \& J. Grimes (Eds.), Best practices in school psychology IV (pp. 243-262). Bethesda, MD: National Association of School Psychologists.

Sims, D. M. \& Lonigan, C. J. (2013). Attention, hyperactivity, and emergent literacy: Different facets of inattention relate uniquely to preschoolers' reading-related skills. Journal of Clinical Child \& Adolescent Psychology, 42, 208-219.

Simonsen, B., Britton, L., \& Young, D. (2010). School-wide positive behavior support in an alternative school setting: A case study. Journal of Positive Behavior Interventions, 12, 180-191.

Simonsen, B., Fairbanks, S., Briesch, A., Myers, D., \& Sugai, G. (2008). Evidence-based practices in classroom management: Considerations for research to practice. Education and Treatment of Children, 31, 351-380.

Stephenson, K. A., Parrila, R. K., Georgiou, G. K., \& Kirby, J. R. (2008). Effects of home literacy, parents' beliefs, and children's task-focused behavior on emergent literacy and word reading skills. Scientific Studies of Reading, 12(1), 24-50.

Stokes, T. F. \& Baer, D. M. (1977). An implicit technology of generalization. Journal of Applied Behavior Analysis, 10, 349-367.

Stokes, T. F., Baer, D. M., \& Jackson, R. L. (1974). Programming the generalization of a greeting response in four retarded children. Journal of Applied Behavior Analysis, 7, 599-610.

Sutherland, K. S., Wehby, J. H., \& Copeland, S. R. (2000). Effect of varying rates of behavior-specific praise on the on-task behavior of students with EBD. Journal of Emotional and Behavioral Disorders, 8, 2-8.

Theodore, L. A., Bray, M. A., \& Kehle, T. J. (2004). A comparative study of group contingencies and randomized reinforcers to reduce disruptive classroom behavior. School Psychology Quarterly, 19, 253-271.

Thorne, S. \& Kamps, D. (2008). Effects of a group contingency intervention on academic engagement and problem behavior of at-risk students. Behavior Analysis in Practice, 1, 12-18.

Thurlow, M. L., Ysseldyke, J. E., Graden, J., \& Algozzine, B. (1984). Opportunity to learn for LD students receiving different levels of special education services. Learning Disability Quarterly, 7, 55-67. 
Tiger, J. H. \& Hanley, G. P. (2004). Developing stimulus control of preschooler mands: An analysis of schedule-correlated and contingency-specifying stimuli. Journal of Applied Behavior Analysis, 37, 517-521.

Tiger, J. H., Hanley, G. P., \& Heal, N. A. (2006). The effectiveness of and preschoolers' preferences for variations of multiple-schedule arrangements. Journal of Applied Behavior Analysis, 39, 475-488.

Tingstrom, D. H., Sterling-Turner, H. E., \& Wilczynski, S. M. (2006). The good behavior game: 1969-2002. Behavior Modification, 30, 225-253.

Vidoni, C. \& Ward, P. (2006). Effects of a dependent group-oriented contingency on middle school physical education students' fair play behaviors. Journal of Behavioral Education, 15, 81-92.

Watkins, C., \& Slocum, T. A. (2004). Elements of Direct Instruction. In N. Machand-Martell, T. Slocum, \& R. Martella (Eds.) Introduction to Direct Instruction. Boston, MA: Allyn-Bacon.

Wharton-McDonald, R., Pressley, M., \& Hampston, J. M. (1998). Literacy instruction in nine first-grade classrooms: Teacher characteristics and student achievement. The Elementary School Journal, 99, 101-128.

Williamson, B. D., Campbell-Whatley, G. D., \& Lo, Y. (2009). Using a random dependent group contingency to increase on-task behaviors of high school students with high incidence disabilities. Psychology in the Schools, 46, 1074-1083.

Wright, R. A. \& McCurdy, B. L. (2012). Class-wide positive behavior support and group contingencies: Examining a positive variation of the good behavior game. Journal of Positive Behavior Interventions, 14, 173-180. 